\title{
NOTCH/WNT CROSS-SIGNALLING REGULATES STEMNESS OF DENTAL PULP STEM CELLS THROUGH EXPRESSION OF NEURAL CREST AND CORE PLURIPOTENCY FACTORS
}

\author{
V. Uribe-Etxebarria ${ }^{1}$, J. Luzuriaga ${ }^{1}$, P. García-Gallastegui ${ }^{1}$, A. Agliano ${ }^{2}$, F. Unda ${ }^{1}$ and G. Ibarretxe ${ }^{1, *}$ \\ ${ }^{1}$ Cell Biology and Histology Department, Faculty of Medicine and Nursing, University \\ of the Basque Country (UPV/EHU), Barrio Sarriena S/N, 48940 Leioa, Spain \\ ${ }^{2}$ Cancer Research UK Cancer Imaging Centre, Division of Radiotherapy and Imaging, \\ The Institute of Cancer Research and The Royal Marsden NHS Foundation Trust, \\ 123 Old Brompton Road, London, SW7 3RP, United Kingdom
}

\begin{abstract}
Dental pulp stem cells (DPSCs) from adult teeth express neural crest (NC) markers together with core transcriptional factors associated with stem cell pluripotency, such as Oct4a, Sox2, c-Myc, Rex1, Stellal Dppa3, Ssea1/Fut4, Lin28 and Nanog. The possibility to boost the natural stemness features of DPSCs by mild methods, that do not involve gene and/or chromatin modification or gene transfection, is highly desirable for cell therapy. Canonical Wnt and Notch are two highly conserved developmental signalling pathways that are involved in NC emergence and stem cell self-renewal. We determined that both pathways coordinate to regulate the expression of core pluripotency and NC factors in DPSCs. Pharmacological inhibition of the Notch pathway for $48 \mathrm{~h}$, by the $\gamma$-secretase inhibitor N-[N-(3,5-Difluorophenacetyl)-L-alanyl]-S-phenylglycine t-butyl ester (DAPT), abolished the expression of NC and core factors. In addition, it induced a silencing of the canonical Wnt signalling and a clear reduction in the stemness potential of DPSCs, as shown by a reduced ability to generate mature, fully differentiated osteoblasts and adipocytes. Conversely, pharmacological activation of the Wnt pathway for $48 \mathrm{~h}$, by either the glycogen synthase kinase 3 beta (GSK3- $\beta$ ) inhibitor 6-bromoindirubin-3'-oxime (BIO) or the human recombinant protein Wnt-3a, not only largely increased the expression of NC and core factors, but also increased the efficiency of DPSCs to differentiate into mature osteoblasts and adipocytes. These results showed that a short preconditioning activation of Wnt/Notch signalling by small molecules and/or recombinant proteins enhanced the stemness and potency of DPSCs in culture, which could be useful for optimising the therapeutic use of these and other tissue-specific stem cells.
\end{abstract}

Keywords: Dental pulp stem cells, multipotency, self-renewal, pluripotency core factors, neural crest, stemness and differentiation, osteogenesis, adipogenesis, Notch, Wnt, BIO, DAPT, Wnt-3a.

*Address for correspondence: Gaskon Ibarretxe, PhD, Cell Biology and Histology Department, Faculty of Medicine and Nursing, University of the Basque Country (UPV/EHU), Barrio Sarriena S/N, 48940 Leioa, Spain. Telephone: +34946013218Ｅmail: gaskon.ibarretxe@ehu.eus

\section{Introduction}

During embryogenesis, neural crest (NC) cells generate most craniomaxillofacial tissues, including all major tissues of the teeth, except the enamel. The remarkable abilities of the NC prompted its designation as "the fourth embryonic layer" (Shyamala et al., 2015; Thomas et al., 2008). Importantly, some NC stem cells with a nondifferentiated phenotype remain in the dental pulp of mature teeth and are known as dental pulp stem cells (DPSCs) (Aurrekoetxea et al., 2015; Gronthos et al., 2002; Gronthos et al., 2000; Ibarretxe et al., 2012; Janebodin et al., 2011; Kaukua et al., 2014; Liu et al., 2015). Other stem cell types with similar properties may be obtained from gingival and periodontal tissues (Abe et al., 2012; Huang et al., 2009; Ibarretxe et al., 2012; Lima et al., 2017; Liu et al., 2015; Petrovic and Stefanovic, 2009) and even from periodontal inflammatory lesions, such as human periapical cysts (Marrelli et al., 2013; Marrelli et al., 2015; Tatullo et al., 2015). Similarly to NC-derived cells, dental stem cells are characterised by the expression of neural crest factors, such as Snail/Snai1, Slug/Snai2, Twist1, Hnk1, Pax3, Neurogenin2 and Sox10 (Kiraly et al., 2009; Schiraldi et al., 2012), and core factors including Oct4a, Sox2, Klf4, Lin28, stage specific embryonic antigen 3 antibody (Ssea1) and Nanog (Atari et al., 2012; Ferro et al., 2012; Janebodin et al., 2011; Kerkis et al., 2006; Rosa et al., 2016). Core factors are fundamental in maintaining stem cell pluripotency (Chambers and Tomlinson, 2009; Takahashi et al., 2007; Yu et al., 2007), thus suggesting that dental stem cells may present some superior features with 
respect to other multipotent stem cell populations of the adult human body (Atari et al., 2011; Atari et al., 2012; Rosa et al., 2016). This could be very relevant for cell therapy because stem cells from dental tissues are known to be easily accessible for extraction and well-tolerated upon grafting, due to their immunesuppressive properties (Pierdomenico et al., 2005). Furthermore, DPSCs are non-tumourigenic even after their immortalisation by telomerase overexpression (Wilson et al., 2015). Finally, given that the dental pulp is rather well preserved in mid-to-advanced age patients, DPSCs are also suitable for autologous therapy (Ibarretxe et al., 2012; Kellner et al., 2014; Wu et al., 2015).

The canonical Notch and Wnt signalling pathways are critical for the maintenance of the stem cell phenotype (Androutsellis-Theotokis et al., 2006; Borghese et al., 2010; Clevers et al., 2014; Perdigoto and Bardin, 2013; Reya and Clevers, 2005). Both pathways also play an important role in the emergence of the NC (Hari et al., 2012; Leung et al., 2016; Rogers et al., 2012; Stuhlmiller and Garcia-Castro, 2012). Dental stem cells present higher levels of core factors and Wnt/Notch activity compared to other mesenchymal stem cells in the adult body (Atari et al., 2012; Huang et al., 2009; Janebodin et al., 2011; Vasanthan et al., 2015). However, the role of these pathways in the maintenance of stemness and self-renewal in DPSCs is still unclear.

Activation of Notch signalling through ligand binding triggers the proteolytic cleavage of Notch receptors, by a disintegrin and metalloproteases (ADAM) followed by $\gamma$-secretases, which results in the cleavage and release of the Notch intracellular domain (NICD) from the membrane. NICD translocates to the nucleus where it directly interacts with CSL/RBPj/ CBF-1 transcription factors to turn on the expression of Notch target genes, such as the hairy/enhancer of split (Hes) family (D'Souza et al., 2010). In the canonical Wnt signalling, the interactions between Wnt protein ligands and Frizzled/LRP receptors lead to the recruitment of axis inhibition protein (AXIN), adenomatous polyposis coli (APC) and glycogen syntase kinase 3 beta (GSK3- $\beta$ ) to the membrane, thus preventing phosphorylation and degradation of $\beta$-catenin. As a result, $\beta$-catenin accumulates in the cytoplasm and translocates into the nucleus, where it interacts with the T-cell factor/lymphoid enhancer factor (TCF/LEF) family factors and leads to the expression of Wnt signalling target genes (Clevers, 2006). Both pathways regulate each other at multiple points (Borggrefe et al., 2016; Fukunaga-Kalabis et al., 2015) and promote the maintenance of self-renewal and inhibition of differentiation in many stem cell types, including DPSCs (Mizutani et al., 2007; Scheller et al., 2008; Yiew et al., 2017).

Pharmacological manipulation of the Notch and Wnt pathways is relatively simple using well-known drugs, such as N-[N-(3,5-Difluorophenacetyl)L-alanyl]-S-phenylglycine t-butyl ester (DAPT)
( $\gamma$-secretase inhibitor; Notch signalling blocker) and BIO (GSK3- $\beta$ inhibitor; Wnt signalling activator), and recombinant activator proteins, such as Wnt-3a. The use of BIO and DAPT has already proven to be a valuable complementary strategy to induce either cellular reprogramming or cellular differentiation (Ichida et al., 2014; Kitajima et al., 2016). Therefore, a thorough understanding of the stemness and differentiation potential of DPSCs and their modulation by cell signalling pathways would be highly desirable to use these cells more efficiently in areas such as regenerative medicine, tissue engineering and drug screening. In this work, we used DAPT and BIO, as well as human recombinant Wnt-3a, as pharmacological modulators to investigate the role of Notch/Wnt in maintaining the stemness and expression of pluripotency core factors in DPSCs, with the goal of optimising existing protocols for differentiation to somatic cells.

\section{Materials and Methods}

\section{DPSC culture}

DPSCs were isolated from human third molars obtained from healthy donors between 15 and 30 years of age. The pulp tissue was isolated by fracture and enzymatic digestion for $1 \mathrm{~h}$ at $37^{\circ} \mathrm{C}$ with $3 \mathrm{mg} / \mathrm{mL}$ collagenase (17018-029; Thermo Fisher Scientific, Boston, MA, USA) and $4 \mathrm{mg} / \mathrm{mL}$ dispase (17105-041; Thermo Fisher Scientific) followed by mechanical dissociation. DPSCs were cultured in Dulbecco's modified Eagle's medium (DMEM) supplemented with $10 \%$ foetal bovine serum (FBS), $1 \mathrm{mM}$ L-glutamine, $100 \mathrm{U} / \mathrm{mL}$ penicillin and $150 \mu \mathrm{g} /$ $\mathrm{mL}$ streptomycin. DPSCs could be amplified and maintained in these conditions for a very long time (> 6 months). However, to avoid cell aging issues, only DPSCs that had been grown in culture for less than 3 months and had accumulated no more than 6 total passages were used. Comparative experiments between control and treatment conditions were always and without exception performed in parallel using DPSCs from the same donor.

\section{Notch and Wnt pathway pharmacological modulation}

To block Notch signalling, $2.5 \mu \mathrm{M}$ DAPT $\gamma$-secretase inhibitor (565784; Calbiochem, San Diego, CA, USA) was added to the culture medium $48 \mathrm{~h}$ prior to the assays, where DAPT-treated DPSCs were compared to DPSCs treated only with the control vehicle dimethyl sulfoxide (DMSO). To overactivate Wnt signalling, $2.5 \mu \mathrm{M}$ 6-bromoindirubin-3'-oxime (BIO), a GSK3- $\beta$ inhibitor (361550; Calbiochem), was used, which was added to the medium $48 \mathrm{~h}$ prior to the assays. BIO-treated cells were compared to DPSCs exposed to $2.5 \mu \mathrm{M}$ inactive analogue methyl-6-bromoindirubin-3' -oxime (MBIO) (361556; Calbiochem). Wnt-3a recombinant protein (5036- 
Table 1a. Primer pairs used. * transcript variants (Pou5f1, Oct4a and Pou5f1p1, Oct4pg1).

\begin{tabular}{|c|c|c|c|c|}
\hline \multicolumn{2}{|c|}{ Primers } & Sequence $5^{\prime}-3^{\prime}$ & $\begin{array}{c}\text { Annealing } \\
\left({ }^{\circ} \mathrm{C}\right)\end{array}$ & $\begin{array}{c}\text { Amplicon } \\
\text { (bp) }\end{array}$ \\
\hline \multirow{2}{*}{$\beta$-actin } & Upstream & GTTGTCGACGACGAGCG & 58.5 & \multirow{2}{*}{93} \\
\hline & Downstream & GCACAGAGCCTCGCCTT & 59.7 & \\
\hline \multirow{2}{*}{ Gapdh } & Upstream & CTTTTGCGTCGCCAG & 60.3 & \multirow{2}{*}{131} \\
\hline & Downstream & TTGATGGCAACAATATCCAC & 60.8 & \\
\hline \multirow{2}{*}{ Notch1 } & Upstream & ATAGTCTGCCACGCC & 54 & \multirow{2}{*}{149} \\
\hline & Downstream & AGTGTGAAGCGGCCA & 54.9 & \\
\hline \multirow{2}{*}{ Notch2 } & Upstream & AAGCCCAGACATTCTTGCAGCTTG & 64.1 & \multirow{2}{*}{107} \\
\hline & Downstream & TCCAGGGCATAATTCCCAACAGGA & 63.7 & \\
\hline \multirow{2}{*}{ Notch3 } & Upstream & ACCCCCAAGAGGCAAGTGT & 61.1 & \multirow{2}{*}{125} \\
\hline & Downstream & AGGATGAAAAAGACTAAAAGGAAGGAA & 59 & \\
\hline \multirow{2}{*}{ Notch4 } & Upstream & GCGATAATGCGAGGAAGATACG & 59.4 & \multirow{2}{*}{118} \\
\hline & Downstream & TCGGAATGTTGGAGGCAGAAC & 60.6 & \\
\hline \multirow{2}{*}{ Hes1 } & Upstream & GGTACTTCCCCAGCACACTT & 59 & \multirow{2}{*}{138} \\
\hline & Downstream & TGAAGAAAGATAGCTCGCGG & 57.7 & \\
\hline \multirow{2}{*}{$\beta$-catenin } & Upstream & GAAGCTGGTGGAATGCAAGC & 60.1 & \multirow{2}{*}{279} \\
\hline & Downstream & GACAGTACGCACAAGAGCCT & 60 & \\
\hline \multirow{2}{*}{ Nestin } & Upstream & GGTCCTAGGGAATTGCAGC & 57.9 & \multirow{2}{*}{144} \\
\hline & Downstream & CTCAAGATGTCCCTCAGCCT & 58.8 & \\
\hline \multirow{2}{*}{ Jagged1 } & Upstream & AGATCTCAATTACTGTGGGAC & 57.1 & \multirow{2}{*}{88} \\
\hline & Downstream & GCAGGAACACTGATATTTGTC & 58.7 & \\
\hline \multirow{2}{*}{ Jagged2 } & Upstream & TCTTGCAAAAACCTGATTGG & 62.6 & \multirow{2}{*}{86} \\
\hline & Downstream & CAGTCGTTGACGTTGATATG & 59.2 & \\
\hline \multirow{2}{*}{ Lef1 } & Upstream & TGCCAAATATGAATTAACGACCCA & 59 & \multirow{2}{*}{151} \\
\hline & Downstream & GAGAAAAGTGCTCGTCACTGT & 58.5 & \\
\hline \multirow{2}{*}{ Oct4* } & Upstream & CGTGAAGCTGGAGAAGGAGA & 60.7 & \multirow{2}{*}{137} \\
\hline & Downstream & CATCGGCCTGTGTATATCCC & 60.1 & \\
\hline \multirow{2}{*}{ c-Myc } & Upstream & GTCAAGAGGCGAACACACAAC & 60 & \multirow{2}{*}{162} \\
\hline & Downstream & TTGGACGGACAGGATGTATGC & 60.1 & \\
\hline \multirow{2}{*}{ Sox2 } & Upstream & ATAATAACAATCATCGGCGG & 61.1 & 90 \\
\hline & Downstream & AAAAAGAGAGAGGCAAACTG & 57.8 & 90 \\
\hline & Upstream & TCTTGAGGAAGTGCTGAG & 56.5 & \\
\hline KIt4 & Downstream & ATGAGCTCTTGGTAATGGAG & 58.3 & $14 /$ \\
\hline
\end{tabular}

WN-010; R\&D Systems, Minneapolis, MN, USA) was added to the DPSCs cultures to overactivate Wnt signalling at two concentrations: $2.5 \mu \mathrm{M}$ and $5 \mu \mathrm{M}$.

\section{Osteogenic differentiation of DPSCs}

The following protocol was used to induce DPSC differentiation to mature osteoblasts: $6 \mu \mathrm{M}$ $\beta$-glicerophosphate (G9422; Sigma-Aldrich, St. Louis, MA, USA), $10 \mathrm{nM}$ dexamethasone (D4902; Sigma-Aldrich) and $52 \mathrm{nM}$ ascorbic acid (127.0250; Merck, Darmstadt, Germany) were added to the cells cultured in DMEM + $10 \%$ FBS for three weeks. The DPSCs had been previously subjected to preconditioning treatment with DMSO, DAPT, MBIO or BIO for $48 \mathrm{~h}$, as described. Terminal osteoblast differentiation was assessed by detection of extracellular calcified bone matrix deposits by Alizarin Red S staining using 2 g/100 mL Alizarin Red S (400480250; Across Organics, Geel, Belgium) at $\mathrm{pH}$ 4.3. The DPSCs were fixed with $10 \%$ formalin (F7503; Sigma-Aldrich) for $30 \mathrm{~min}$. Then, cells were incubated with Alizarin Red S for 45 min before being washed four times with PBS to remove any background staining. The Alizarin Red S absorbance at $450 \mathrm{~nm}$ was quantified using a Synergy HT MultiMode Microplate Reader (BioTek, Winooski, VT, USA). Also, alkaline phosphatase (ALP) staining was used to assess osteoblast differentiation, as this enzymatic activity is present in mature bone matrix-secreting cells. One SIGMA FAST ${ }^{\mathrm{TM}}$ BCIP/ NBT (5-bromo-4-chloro-3-indolyl phosphate/nitro blue tetrazolium) tablet (B5655-5ATB; Sigma-Aldrich) was dissolved in $10 \mathrm{~mL}$ milliQ water and added to the DPSCs fixed for 1 min with $10 \%$ formalin. Next, cells were washed with PBS containing $0.05 \%$ Tween 20 (STBB3609; Sigma-Aldrich). ALP activity was quantified by measuring the absorbance at $405 \mathrm{~nm}$ with a Synergy HT Multi-Mode Microplate Reader (BioTek).

\section{Adipogenic differentiation of DPSCs}

To induce adipogenic differentiation, DPSC cultures were treated with $0.5 \mathrm{mM}$ 3-Isobutyl-1methylxanthine (IBMX) (I5879; Sigma-Aldrich), 
Table 1b. Primer pairs used.

\begin{tabular}{|c|c|c|c|c|}
\hline \multicolumn{2}{|c|}{ Primers } & Sequence $5^{\prime}-3^{\prime}$ & $\begin{array}{c}\text { Annealing } \\
\left({ }^{\circ} \mathrm{C}\right)\end{array}$ & $\begin{array}{c}\text { Amplicon } \\
\text { (bp) }\end{array}$ \\
\hline \multirow[t]{2}{*}{ Nanog } & Upstream & GTCAAGAAACAGAAGACCAG & 56.4 & \multirow{2}{*}{184} \\
\hline & Downstream & GCCACCTCTTAGATTTCATTC & 59.2 & \\
\hline \multirow[t]{2}{*}{ Lin28 } & Upstream & CTGGTGGAGTATTCTGTATTG & 56.2 & \multirow[t]{2}{*}{81} \\
\hline & Downstream & ACCTGTCTCСТTTTGATCTG & 58.3 & \\
\hline \multirow[t]{2}{*}{ Rex1 } & Upstream & TATCTCAACCTGTTCATCGAG & 59.3 & \multirow[t]{2}{*}{130} \\
\hline & Downstream & CCACATTCAGGTAGATGTTC & 56.9 & \\
\hline \multirow[t]{2}{*}{ Ssea1/Fut4 } & Upstream & ACAAAATCATCTGTTGGGAC & 58.9 & \multirow[t]{2}{*}{85} \\
\hline & Downstream & AGCAGATAAGCACTTTCAAC & 56.2 & \\
\hline \multirow[t]{2}{*}{ Stella/Dppa3 } & Upstream & GAGGAGTAAGAACATTGCTG & 56.5 & \multirow[t]{2}{*}{133} \\
\hline & Downstream & CTTGATTCCTTCTTAACTCCC & 58.3 & \\
\hline \multirow[t]{2}{*}{ Snail/Snai1 } & Upstream & AACAATGTCTGAAAAGGGAC & 58.1 & \multirow[t]{2}{*}{94} \\
\hline & Downstream & ATAGTTCTGGGAGACACATC & 55.4 & \\
\hline \multirow[t]{2}{*}{ Slug/Snai2 } & Upstream & AAACAACCTGAAGACTTGTG & 56.8 & \multirow[t]{2}{*}{157} \\
\hline & Downstream & TTCTTTGTACAGTGGTTTGG & 57.7 & \\
\hline \multirow[t]{2}{*}{ Sox10 } & Upstream & ACTTAGTGGAGTTCTCATCC & 54.7 & \multirow[t]{2}{*}{106} \\
\hline & Downstream & AAGAATGAGGTTATTGGCAC & 58.1 & \\
\hline \multirow[t]{2}{*}{ Pax3 } & Upstream & ATCAACTGATGGCTTTCAAC & 59.2 & \multirow[t]{2}{*}{120} \\
\hline & Downstream & CAGCTTGTGGAATAGATGTG & 58.3 & \\
\hline \multirow[t]{2}{*}{ Pax7 } & Upstream & AGGAGTACAAGAGGGAAAAC & 56.4 & \multirow[t]{2}{*}{108} \\
\hline & Downstream & TAATCGAACTCACTGAGGG & 57.8 & \\
\hline \multirow[t]{2}{*}{ Neurogenin2 } & Upstream & AGGGAAGAGGACGTGTTAGTGC & 61.9 & \multirow[t]{2}{*}{225} \\
\hline & Downstream & GCAATCGTGTACCAGACCCAG & 61 & \\
\hline \multirow[t]{2}{*}{ Twist1 } & Upstream & CTAGATGTCATTGTTTCCAGAG & 57.9 & \multirow[t]{2}{*}{136} \\
\hline & Downstream & CCCTGTTTCTTTGAATTTGG & 60.9 & \\
\hline \multirow[t]{2}{*}{ Wnt3 } & Upstream & CTGTGACTCGCATCATAAG & 56.8 & \multirow[t]{2}{*}{186} \\
\hline & Downstream & ATGTGGTCCAGGATAGTC & 54.3 & \\
\hline \multirow[t]{2}{*}{ Wnt1 } & Upstream & CTATTTATTGTGCTGGGTCC & 58.5 & \multirow[t]{2}{*}{125} \\
\hline & Downstream & AGAAACTGAGGAGAGAAGAG & 54.2 & \\
\hline \multirow[t]{2}{*}{ Hnk1 } & Upstream & TGTGAGTGCTGGTAATGAG & 57.2 & \multirow[t]{2}{*}{169} \\
\hline & Downstream & АСТGСССТСАТССТТАТG & 57.5 & \\
\hline
\end{tabular}

$1 \mu \mathrm{g} / \mathrm{mL}$ insulin (91077C; SAFC Biosciences, St. Louis, MA, USA) and $1 \mu \mathrm{M}$ dexamethasone (D4902; Sigma-Aldrich) for four weeks after a preconditioning treatment with DMSO, DAPT, MBIO or BIO for $48 \mathrm{~h}$. Subsequently, DPSCs were fixed with $10 \%$ formalin for 10 min and then washed with PBS containing $60 \%$ isopropanol. Lipid droplets in mature adipocytes were detected using Oil Red O staining solution, which contained 5.14 $\mu \mathrm{M}$ Oil Red O stock (O-0625; Sigma-Aldrich) diluted in milliQ water. Cells were stained for $10 \mathrm{~min}$ and the Oil Red $\mathrm{O}$ absorbance was measured at $490 \mathrm{~nm}$ using a Synergy HT Multi-Mode Microplate Reader (BioTek).

RNA extraction, conventional RT-PCR and quantitative Real-Time PCR (qPCR)

Cell pellets were frozen and stored at $-80{ }^{\circ} \mathrm{C}$. Total RNA was extracted from the cells using the RNeasy kit (74104; Qiagen, Hilden, Germany) and purity was checked by calculating the 260/280 absorbance ratio using the Nanodrop Synergy HT (BioTek). cDNA (50 $\mathrm{ng} / \mu \mathrm{L}$ ) was obtained by reverse transcription of total extracted RNA using the iScript cDNA kit (1708890; BioRad, Hercules, CA, USA) with the following reagents: iScript Reverse Transcriptase $(1 \mu \mathrm{L}), 5 \times$ iScript Reaction Mix $(4 \mu \mathrm{L})$ and Nucleasefree water (variable) to a final volume of $20 \mu \mathrm{L}$. Gene expression was analysed using $1 \mu \mathrm{L}$ of cDNA ( $5 \mathrm{ng} / \mu \mathrm{L})$ diluted in $4 \mu \mathrm{L}$ of My TaqTM Red Mix (BIO-25043, Bioline, St. Petersburg, Russia), $1 \mu \mathrm{L}$ of primers $(0.625 \mu \mathrm{M})$ and Nuclease Free Water, for a total volume reaction of $10 \mu \mathrm{L}$ for a conventional RT-PCR. Amplification products were separated by electrophoresis in a $2 \%$ agarose gel. qPCR experiments were conducted in an $\mathrm{iCyclerMyiQ}^{\mathrm{TM}}$ Single-Color Real-Time PCR Detection System (BioRad) using $4.5 \mu \mathrm{L}$ of Power SYBR ${ }^{\circledR}$ Green PCR Master Mix 2× (4367659; Applied Biosystems ${ }^{\mathrm{TM}}$ Applied Biosystems, Carlsbad, CA, USA), $0.5 \mu \mathrm{L}$ of primers $(0.3125 \mu \mathrm{M}), 0.3 \mu \mathrm{L}$ of $\mathrm{CDNA}(1.5 \mathrm{ng} / \mu \mathrm{L})$ and Nuclease Free water for a total volume reaction of $10 \mu \mathrm{L}$. All primers were obtained from public databases and checked for optimal efficiency (>90\%) under our qPCR experimental conditions. The relative expression of each gene was calculated using the standard $2^{-\Delta \Delta C t}$ method (Livak and Schmittgen, 2001) and normalised to the average between $\beta$-actin and Gapdh, as internal controls. All reactions were 
performed in triplicate. $\mathrm{qPCR}$ was run on an $\mathrm{ABI}$ PRISM $^{\circledR} 7000$ (Thermo Fisher Scientific). Data were processed by CFX Manager ${ }^{\mathrm{TM}}$ software (BioRad). We assessed that all qPCR reactions yielded only one amplification product by the melting curve method. Primer pairs used were obtained through the PrimerBlast method (Primer Bank) and they are listed in Table $1 \mathbf{a}, \mathbf{b}$.

\section{Protein extraction}

Cells were washed several times with $0.9 \% \mathrm{NaCl}$ and the proteins were extracted with $100 \mu \mathrm{L}$ of lysis buffer [50 mM Tris-HCl pH 7.5, 1 mM EDTA, 150 mM $\mathrm{NaCl}, 0.5 \%$ sodium deoxycholate, $0.1 \%$ SDS, $1 \%$ IGEPAL ${ }^{\circledR}$ CA-630 in $\mathrm{dH}_{2} \mathrm{O}$ and $1: 100$ Proteinase Inhibition Cocktail Set III (539134; Calbiochem)]. Protein quantification was performed before each Western Blot (WB) using the DC ${ }^{\mathrm{TM}}$ Protein Assay (5000112; Bio Rad).

\section{Western Blot (WB)}

Samples were diluted in NuPAGE sample buffer (NP0007; Novex, Life technologies, Carlsbad, CA, USA) and loaded onto a 4-12 \% Invitrogen NuPAGE BisTris Gel (1 mm $\times 10$ wells; NP032180X, Novex, Life Technologies). Subsequently, they were transferred onto $0.45 \mu \mathrm{m}$-pore nitrocellulose membranes (Inmmobilon ${ }^{\circledR}$ Transfer Membranes; Millipore, St. Charles, MO, USA) using a XCell Sure Lock Electrophoresis machine (NP0007; Novex, Life Technologies). For WB analyses, the following antibodies were used: 1 : 1000 rabbit anti $\beta$-actin (4967; Cell Signaling Technology (CST), Danvers, MA, USA), 1 : 10000 mouse anti-Gapdh (MAB374; Millipore), 1 : 2000 rabbit anti-PARP (9542S; CST), $1: 500$ rabbit anti-Sox2 (GTX101506; GeneTex, Irvine, CA, USA), 1 : 1000 rabbit anti-Nanog 1,2 (D73G4; CST, 1 : 1000 rabbit anti-Notch 1-receptor intracellular domain (N1ICD) (ab8925; Abcam, Cambridge, UK), 1 : 4000 rabbit anti-total $\beta$-catenin (ab6302; Abcam) and 1 : 500 mouse anti-active $\beta$-catenin (05-665; Millipore). The secondary antibodies (P0260; DAKO, Hovedstaden, Denmark; NA9340, GE Healthcare, Amersham, UK) were used at a $1: 2000$ dilution. The membranes were stripped using Red Blot reagent (M2504; Inmmobilon ${ }^{\circledR}$ EMD, Millipore).

\section{Immunofluorescence (IF)}

DPSCs cultured on glass coverslips were fixed with $4 \%$ paraformaldehyde for $10 \mathrm{~min}$ and washed with PBS. Blocking was performed by $10 \mathrm{~min}$ incubation with Normal Goat Serum (501972; Thermo Fisher Scientific). Next, DPSCs were incubated overnight at $4{ }^{\circ} \mathrm{C}$ with primary antibodies diluted in PBS $+2 \%$ BSA $+0.1 \%$ Triton X-100. The rabbit anti-N1ICD (ab8925; Abcam), anti-Oct4 (ab19857; Abcam), antic-Myc (ab32[9E10]; Abcam), anti-Ki67 (ab15580; Abcam) and anti-total $\beta$-catenin (ab6302; Abcam) antibodies were used at $1: 200,1: 100,1: 1000,1: 100$ and $1: 3000$ dilutions, respectively. Goat anti-rabbit Alexa Fluor (488: A11012; 594: A11012; Invitrogen,
Carlsbad, CA, USA) were employed as secondary antibodies at a 1 : 200 dilution, followed by DAPI, used to counterstain cell nuclei. Images were captured with an epifluorescence ZEISS Axioskop (ZEISS, Jena, Germany) operated with Nikon NIS-Elements and an Apotome Confocal Microscope (ZEISS) operated with Nikon DS-Qi1Mc software (Nikon, Tokyo, Japan). Samples fluorescence intensities were quantified by Fiji-ImageJ (Schindelin et al., 2012) after background subtraction.

\section{Cell proliferation and death assays}

$20 \mu \mathrm{g} / \mathrm{mL}$ propidium iodide (PI; Sigma-Aldrich) was used to detect cell death and $5 \mu \mathrm{M}$ calcein-AM (Life Technologies) to detect cell viability. Both fluorescent dyes were incubated for $30 \mathrm{~min}$ at $37^{\circ} \mathrm{C}$ in culture medium and subsequently cells were washed 3 times with PBS. Fluorescence quantification was calculated by microfluorimetry, measuring light emission at $495 \mathrm{~nm}$ (calcein-AM: green fluorescence) and $630 \mathrm{~nm}$ (PI: red fluorescence) in a Fluoroskan Ascent plate reader (Thermo Fisher Scientific).

\section{Statistical analyses}

Statistical analyses were performed with Excel, IBM SPSS Statistics v.9 (SPSS, Chicago, IL, USA) and GrapH Pad v.6 software (Graph Pad Inc., La Jolla, CA, USA). All data sets were subjected to a KolmogorovSmirnov normality test prior to analysis. For small sample sizes, non-parametric tests were chosen by default. Comparisons between only two groups were made using U-Mann Whitney test. Comparisons between multiple groups were made using KruskalWallis followed by Dunn's post hoc test. $p \leq 0.05$ was considered to be statistically significant.

\section{Results}

\section{Notch activity was required for the expression of core pluripotency factors and self-renewal of DPSCs}

Control DPSCs showed detectable amounts of core pluripotency factors, such as Oct4 (Pou5f1 and Pou5f1p1), Sox2, Nanog, Lin28, Rex1, Stella, Ssea1 and c-Myc, measured by RT-PCR amplicon bands. To assess whether DAPT treatment would affect the expression of core factors in DPSCs, we exposed the DPSC cultures to transient applications of $2.5 \mu \mathrm{M}$ DAPT for $48 \mathrm{~h}$. Interestingly, for many of these factors, the RT-PCR bands were significantly reduced or lost when the DPSCs were treated with DAPT (Fig. 1a). As an internal control to assess Notch activity, we examined the expression of the Notch target gene Hes1. A clear decrease in Hes1 expression was consistently observed following DAPT treatment. Next, these changes were validated by qPCR, confirming that all core factors had significantly decreased levels of expression when DPSCs were exposed to DAPT. In some cases, such as that of Rex1 or Ssea1 expression, the decrease in expression 

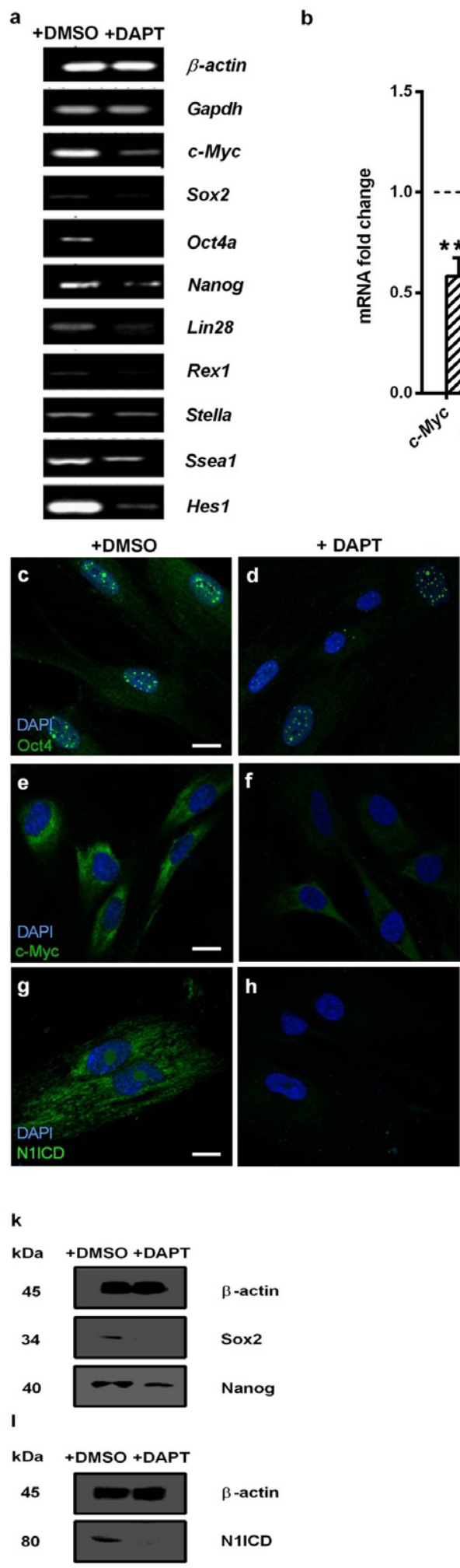

b

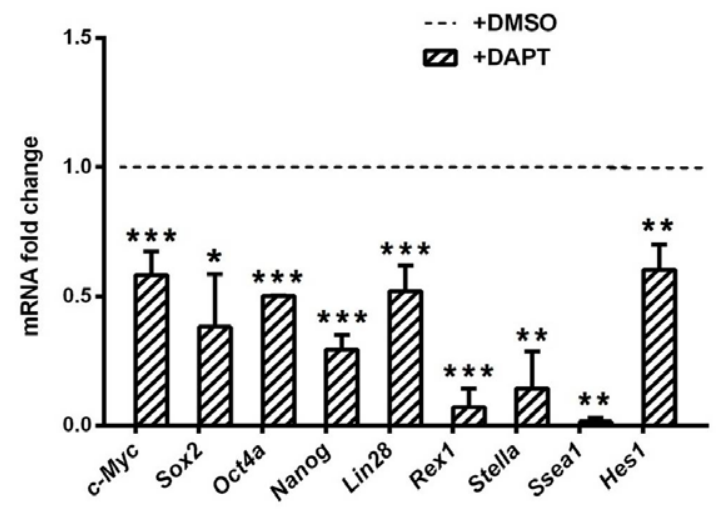

i
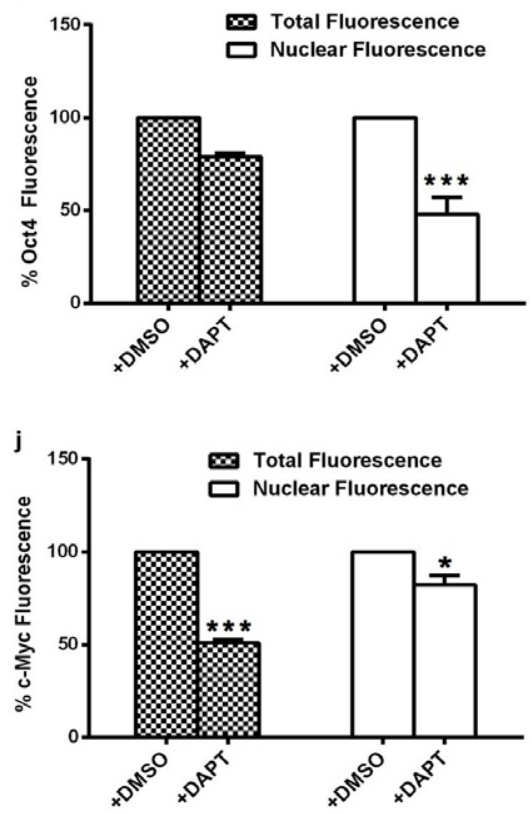

m

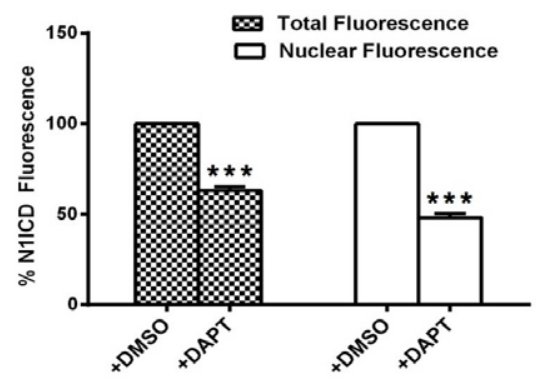

Fig. 1. Notch inhibition by DAPT reduced the expression of core pluripotency factors in DPSCs. (a) RTPCR revealed differences in the expression of $c-M y c$, Sox2, Nanog, Oct4a and Hes1 expression following DAPT exposure. (b) qPCR analysis confirmed a decrease in c-Myc, Sox2, Nanog, Oct4a, Rex1, Stella, Ssea1 and Hes1 transcripts between the control (DMSO) and DAPT conditions. Data were normalised to reference $\beta$-actin and Gapdh levels and presented as the mean $+\operatorname{SEM}(n=3)$. The dashed line represented normalised gene expression in control conditions. (c-h) IF images of DPSCs grown for $48 \mathrm{~h}$ in presence or absence of DAPT and stained for (c,d) Oct4, (e,f) c-Myc and (g,h) N1ICD (in green). DAPI labelled cell nuclei (in blue). Scale bar $=20 \mu \mathrm{m}$. $(\mathbf{i}, \mathbf{j}, \mathbf{m})$ Bar charts showing relative total and nuclear (i) Oct4, (j) c-Myc and (m) N1ICD fluorescence in control and DAPT-treated DPSCs. The data are presented as mean + SEM $(n=3)$. Representative WB showing (k) Sox2, Nanog and (1) active cleaved N1ICD. $\beta$-actin was used as protein loading control. ${ }^{*} p<0.05,{ }^{* *} p<0.01$, ${ }^{* * *} p<0.001$. U-Mann Whitney test. 
was more than $90 \%$ with respect to control (Fig. 1b). Finally, these changes were also corroborated by IF and WB, where Oct4 (nuclear active form Oct4-a; Atlasi et al., 2008; Ferro et al., 2012; Liedtke et al., 2007), Sox2, Nanog (canonical isoform 1; Saunders et al., 2013; Wang et al., 2008), c-Myc and Notch activity marker N1ICD, had also a consistently reduced expression at the protein level (Fig. 1c-1).

The proliferation rates of DPSCs in the presence or absence of DAPT were compared, to verify if the decreased expression of core factors in DPSCs also reflected a decreased ability for self-renewal and proliferation. DPSCs were incubated with a mixture of calcein-AM/PI, after being cultivated for $48 \mathrm{~h}$ in the presence or absence of DAPT. No PI fluorescence was detectable in either condition, indicating that cell viability was not compromised by DAPT treatment. However, calcein fluorescence was reduced by approximately $40 \%$ in the DAPT conditions compared to control (Fig. 2a-c). To corroborate this result, the number of proliferative cells positive for Ki67, a marker of cell proliferation present during the

$+\mathrm{DMSO}$

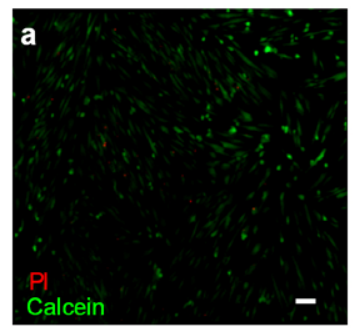

C

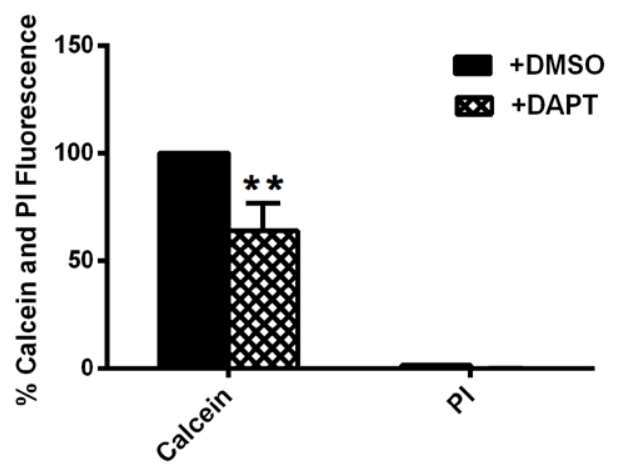

G1, S, G2 and M phases of the cell cycle, but absent from non-dividing cells (G0), was evaluated. Ki67 labelling was significantly lower in the DAPT-treated DPSCs with respect to controls, thus indicating a reduction in the amount of cycling proliferative cells (Fig. 2e-g). Finally, it was confirmed that, despite inducing a reduction in DPSC proliferation, DAPT treatment did not cause any genomic damage or apoptotic cell death. The cleaved poly-ADP ribose polymerase (PARP) levels were assessed by WB and resulted negative in all conditions (Fig. 2d). Taken together, these results suggested that Notch inhibition caused a decrease in the expression of core pluripotency factors in DPSCs, which resulted in decreased self-renewal and proliferation capacities, without affecting cell viability.

Notch and $W n t / \beta$-catenin signalling interacted and positively regulated each other in DPSCs

To assess whether Notch signalling interacted with Wnt/ $\beta$-catenin signalling in DPSCs, the effect of DAPT treatment on the expression of Wnt signalling

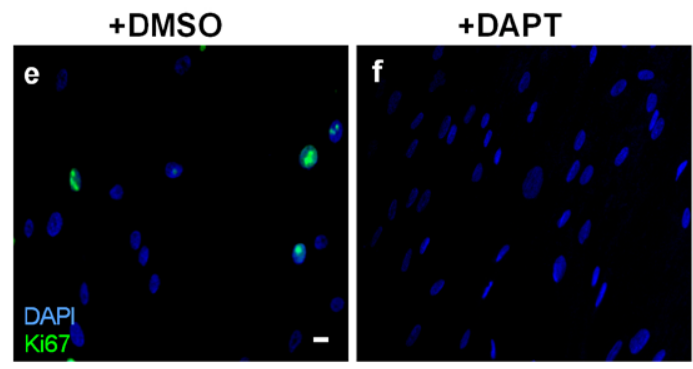

g

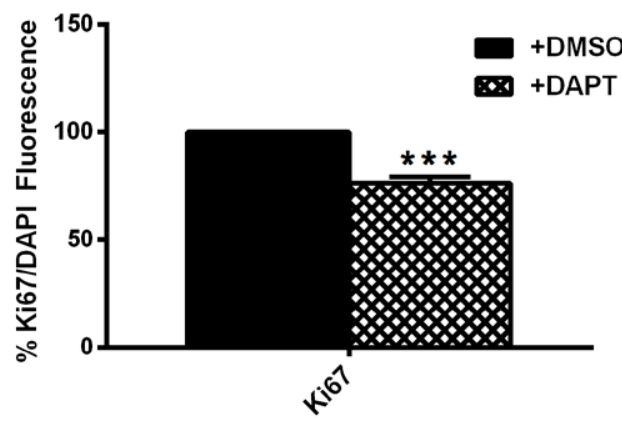

d

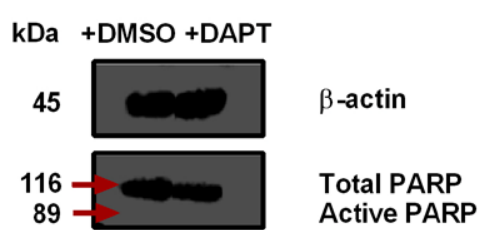

Fig. 2. Cell proliferation and cell death analysis in DPSCs exposed to DAPT. (a,b) Calcein-AM (green) and PI (red) staining of DPSC grown in control and DAPT for $48 \mathrm{~h}$. Scale bar $=200 \mu \mathrm{m}$. (c) Quantification of relative calcein-AM and PI fluorescence. Data are presented as mean + SEM $(n=7)$. (d) WB showing absence of cleaved PARP protein ( $89 \mathrm{kDa}$; red arrow) in both DMSO and DAPT conditions in comparison with total inactive non-cleaved PARP (116 kDa), which was well detected. (e,f) IF for Ki67 in DMSO and DAPT conditions. Scale bar $=20 \mu \mathrm{m}$. (g) Quantification of Ki67 labelling in DAPT-treated and control DPSCs. Data are presented as mean $+\operatorname{SEM}(n=7) .{ }^{* *} p<0.01,{ }^{* * *} p<0.001$. U-Mann Whitney test. 
targets genes was studied by qPCR. Notch1-4 receptor expression was negatively affected by the treatment, whereas the expression of the Notch ligand Jagged1 was unaffected (Fig. 3a,b). These results showed an overall downregulation of Notch signalling in DPSCs induced by DAPT treatment. Intriguingly, we also found out that DAPT treatment reduced the expression of the canonical Wnt mediators Wnt-3a and $\beta$-catenin and also that of the Wnt target gene
Lef1 by $~ 50-70 \%$ compared to their respective control values (Fig. 3a,b). To confirm this result, $\beta$-catenin protein levels were assessed both by WB and IF. A significant decrease in the amount of both total and nuclear active $\beta$-catenin was found in DPSCs exposed to DAPT for $48 \mathrm{~h}$ (Fig. 3c-f). Therefore, Notch inhibition resulted in a parallel Wnt/ $\beta$-catenin signalling inhibition in DPSCs.

\section{+DMSO +DAPT}
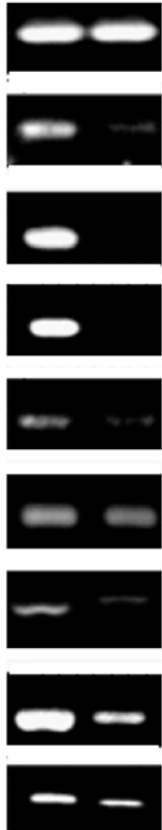

+DMSO

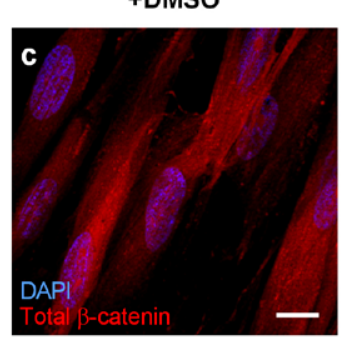

f

Lef1 b

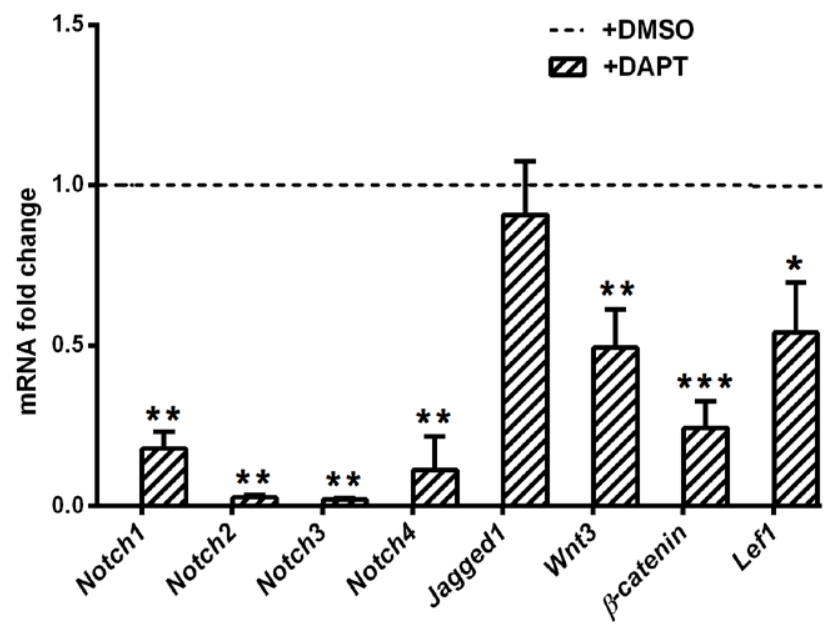

$\beta$-catenin
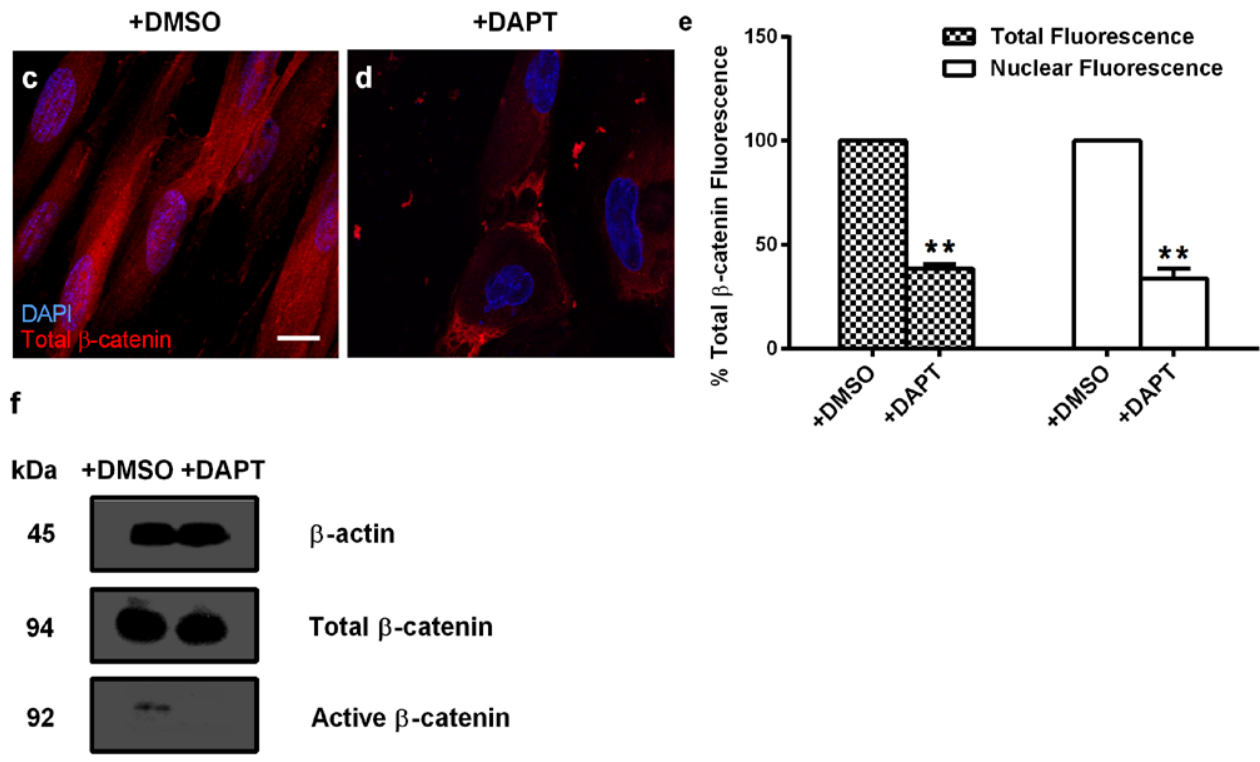

$\beta$-actin

Total $\beta$-catenin

Active $\beta$-catenin

Fig. 3. Notch inhibition by DAPT negatively regulated Wnt/ $\beta$-catenin signalling in DPSCs. (a) RT-PCR revealed differences in the expression of key Wnt signalling mediators and targets Wnt-3a, $\beta$-catenin and Lef1 in DPSCs following DAPT exposure. (b) qPCR confirmed a decrease in both Notch receptors and Wnt factors between control (DMSO) and DAPT conditions. Data were normalised to $\beta$-actin and Gapdh levels and presented as the mean $+\operatorname{SEM}(n=4)$. The dashed line represented normalised gene expression in control conditions. (c,d) IF images of total $\beta$-catenin in DAPT-treated DPSCs compared with controls. Scale bar $=20 \mu \mathrm{m}$. (e) Bar chart showing relative total and nuclear $\beta$-catenin fluorescence in control and DAPT conditions. (f) WB of total and nuclear active $\beta$-catenin in control and DAPT-treated DPSCs. $\beta$-actin was used as a protein loading control. ${ }^{*} p<0.05,{ }^{* *} p<0.01,{ }^{* *} p<0.001$. U-Mann Whitney test. 


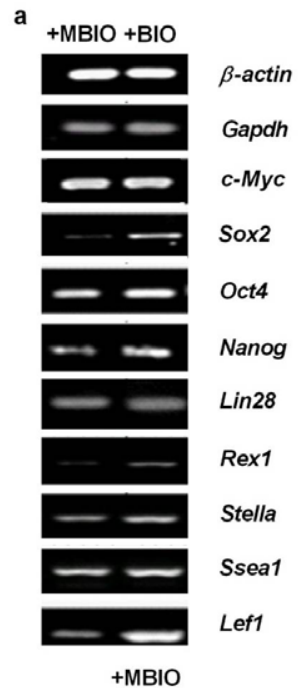

b
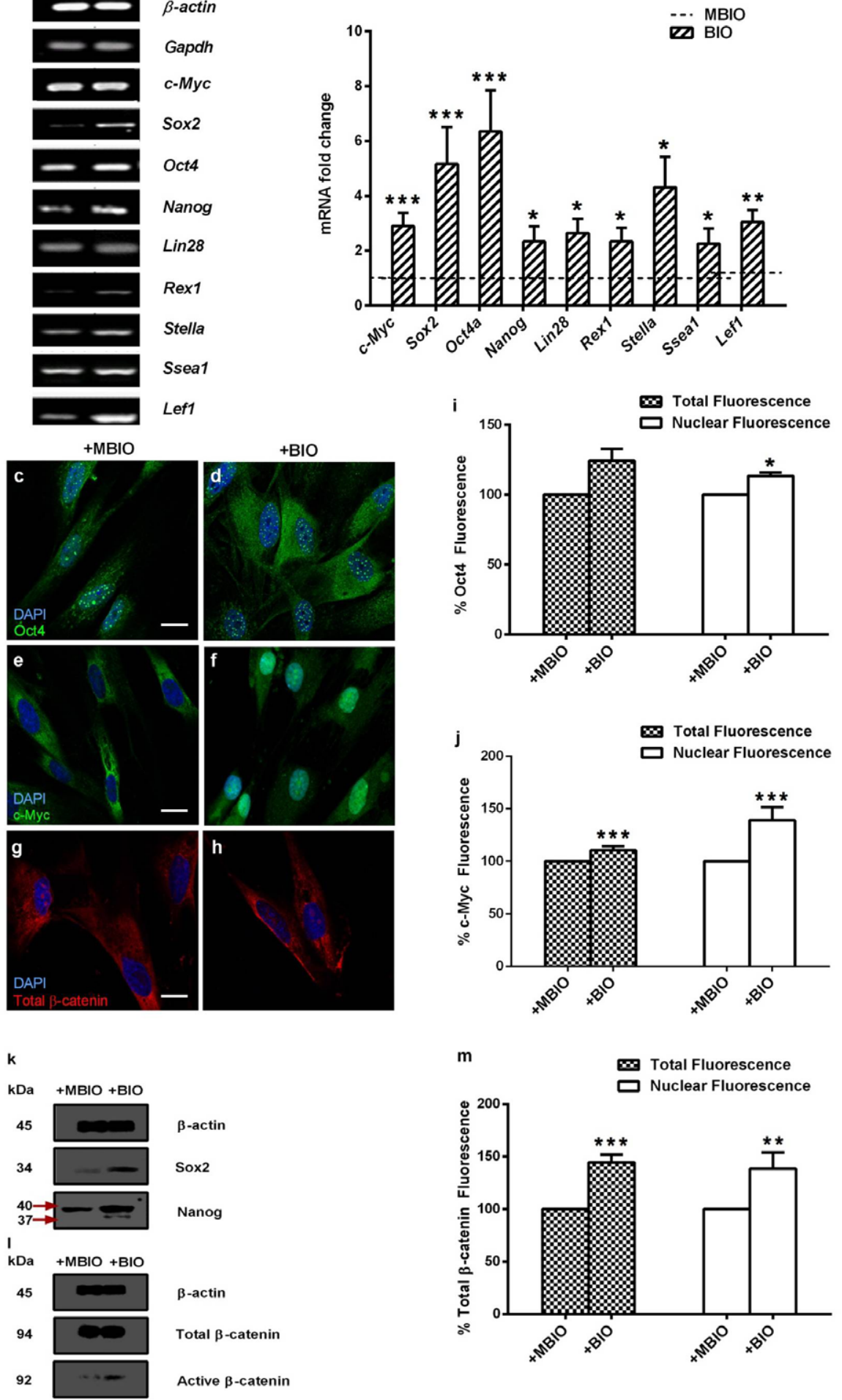

Fig.4. Wnt activation by BIO led to increased expression of core pluripotency factors in DPSCs. (a) RT-PCR revealed differences in the expression of $c-M y c$, Sox2, Nanog, Oct4 and Lef1 following BIO exposure. (b) qPCR analysis confirmed an increase in c-Myc, Sox2, Nanog, Oct4a, Rex1, Stella, Ssea1 and Lef1 expression between control (MBIO) and BIO conditions. Data were normalised to $\beta$-actin and Gapdh levels and presented as the mean $+\operatorname{SEM}(n=3)$. The dashed line represented normalised gene expression in control conditions. (c-h) IF images of DPSCs grown in the presence of MBIO or BIO for $48 \mathrm{~h}$ and stained for $(\mathbf{c}, \mathbf{d})$ Oct4, $(\mathbf{e}, \mathbf{f}) \mathrm{c}-\mathrm{Myc}$ and $(\mathbf{g}, \mathbf{h})$ total $\beta$-catenin. DAPI labelled nuclei in blue. Scale bar $=20 \mu \mathrm{m} .(\mathbf{i}, \mathbf{j}, \mathbf{m})$ Bar charts showing relative total and nuclear (i) Oct4 (j) c-Myc and (m) total $\beta$-catenin fluorescence in MBIO and BIO-treated DPSCs. Data are presented as the mean + SEM $(n=3)$. $(\mathbf{k}, \mathbf{l})$ Representative WB showing an increase in (k) Sox2, native Nanog1 and Nanog2 isoforms, with slightly different molecular weights, and (1) in both total $\beta$-catenin and active $\beta$-catenin protein expression. $\beta$-actin was used as a protein loading control. ${ }^{*} p<0.05,{ }^{* *} p<0.01,{ }^{* * *} p<0.001$. U-Mann Whitney test. 
BIO-induced Wnt activation enhanced the expression of pluripotency core factors in DPSCs To investigate whether $\mathrm{Wnt} / \beta$-catenin activation would enhance the expression of pluripotency core factors in DPSCs, we used BIO treatment for $48 \mathrm{~h}$ to hyperactivate Wnt signalling by inhibiting $\beta$-catenin degradation. As a control for treatment efficacy, BIO-treated DPSCs showed increased levels of both total and active $\beta$-catenin protein, whereas other Wnt targets, such as Lef1, also demonstrated consistently increased expression (Fig. $4 \mathbf{a}, \mathbf{b}, \mathbf{g}, \mathbf{h}, \mathbf{k}-\mathbf{l}$ ). Therefore, BIO induced a strong hyperactivation of Wnt signalling in DPSCs. Then, the expression of pluripotency core factors in BIO-treated DPSCs by RT-PCR and qPCR was assessed. It was determined that $\mathrm{BIO}$ also induced overexpression of pluripotency factors at both the transcript (Fig. 4a,b) and protein levels (Fig. 4c-k).

In addition to boosting the expression of core pluripotency factors, BIO increased the
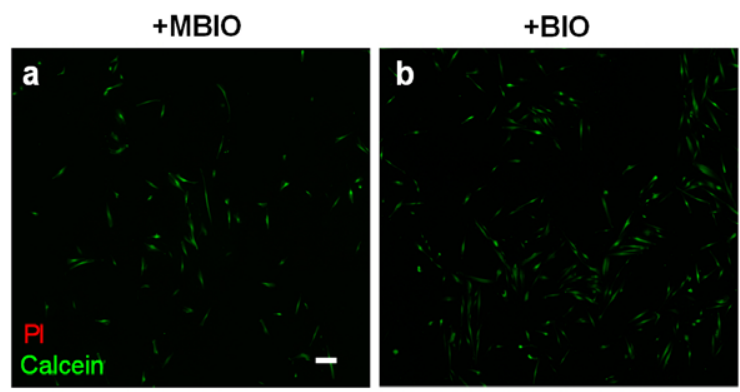

C

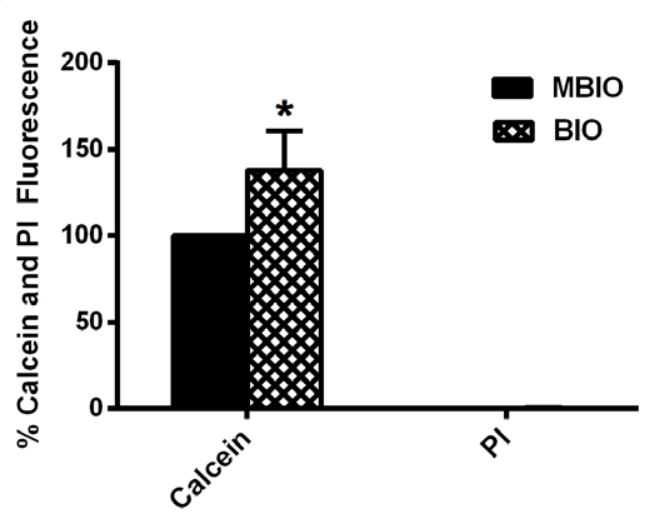

d

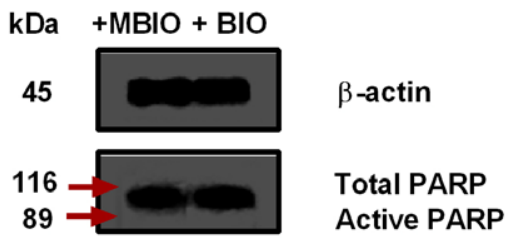

proliferation ability of DPSCs. As shown by the calcein/PI assay, the number of viable cells in culture significantly increased after BIO treatment (Fig. 5ac). Consistently, the Ki67/DAPI fluorescence ratio increased in response to $\mathrm{BIO}$ treatment, indicating a greater proportion of active dividing cells (Fig. 5e-g). Neither PI-positive cells nor an active PARP signal in BIO-treated cells were detected (Fig. 5d). Together, these experiments demonstrated that Wnt activation by BIO treatment increased the proliferation and selfrenewal capacities of DPSCs without compromising their viability and genomic integrity.

\section{Wnt activation by BIO induced Notch upregulation in DPSCs}

Given that DAPT treatment affected Wnt signalling in DPSCs, the question whether Notch activity would also be affected in BIO-treated DPSCs needed addressing. It was found that in BIO-treated DPSCs, most Notch receptors did not undergo any change
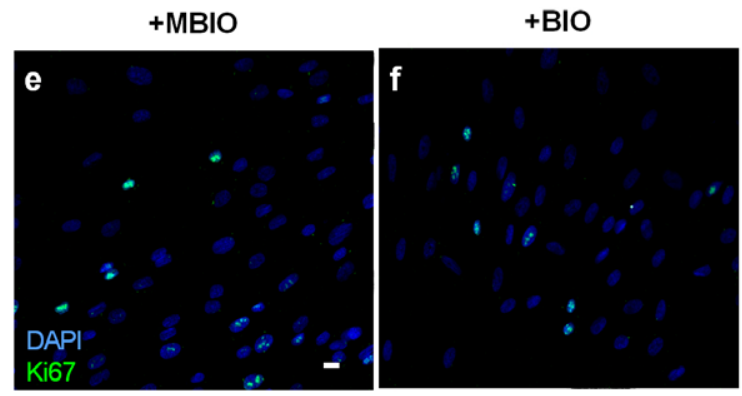

g

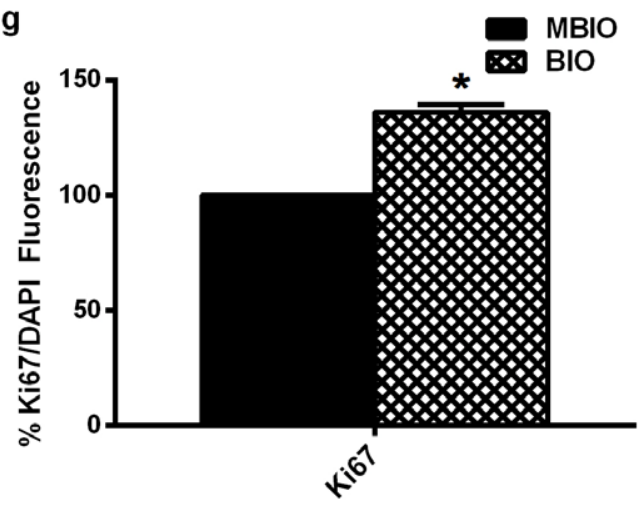

Fig. 5. Cell proliferation and cell death analysis in DPSCs exposed to BIO. (a,b) Calcein-AM (green) and PI (red) staining of DPSCs grown in MBIO and BIO conditions for $48 \mathrm{~h}$. Scale bar $=200 \mu \mathrm{m}$. (c) Quantification of relative calcein-AM and PI fluorescence. Data are presented as mean + SEM $(n=7)$. (d) WB showing absence of cleaved PARP protein (89 kDa; red arrow) in both $\mathrm{MBIO}$ and $\mathrm{BIO}$ conditions, in comparison with total inactive non-cleaved PARP (116 kDa), which was well detected. (e,f) IF for Ki67 in MBIO and BIO conditions. Scale bar $=20 \mu \mathrm{m}$. (g) Quantification of Ki67 labelling in MBIO- and BIO-treated DPSCs. Data are presented as mean $+\operatorname{SEM}(n=7) .{ }^{*} p<0.05$. U-Mann Whitney test. 
in expression, except the Notch2 receptor, which was found to be slightly upregulated at the transcript level (Fig. 6a,b). However, the Notch canonical ligand Jagged1 underwent a much larger 8-fold increase in expression, when the DPSCs were exposed to BIO, followed by $W n t-3 a$ and $\beta$-catenin with a $\sim 5$-fold increased expression (Fig. 6b). Moreover, Hes1 was also prominently upregulated, which constituted solid evidence that Notch signalling was being hyperactivated by $\mathrm{BIO}$ treatment (Fig. 6b). Notch signalling upregulation at the protein level was also tested, using an antibody for active cleaved N1ICD. Increased levels of N1ICD were detected for BIOtreated DPSCs by both WB and IF (Fig. 6c-f). a
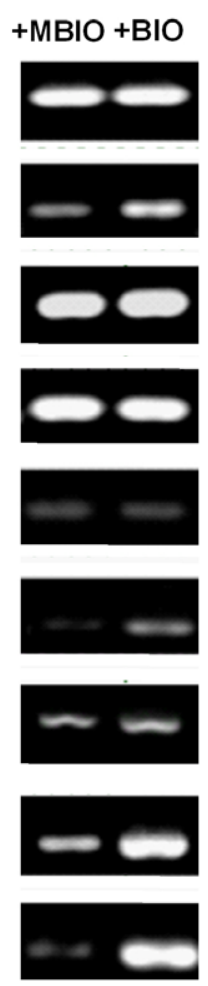

Hes1

Wnt3 b

$\beta$-actin

Notch1

Notch2

Notch3

Notch4

Jagged1

$\beta$-catenin

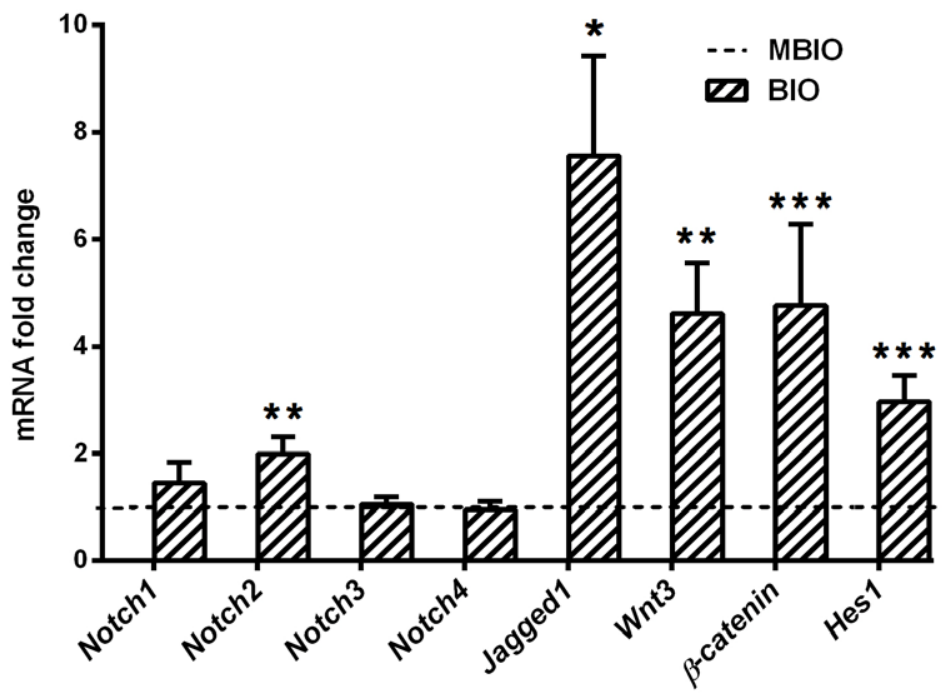

$+\mathrm{MBIO}$

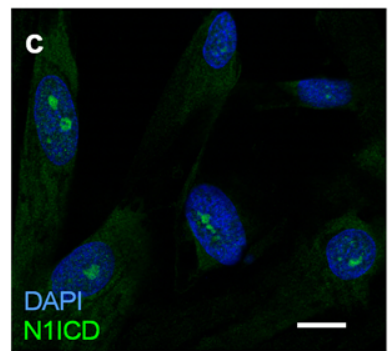

f

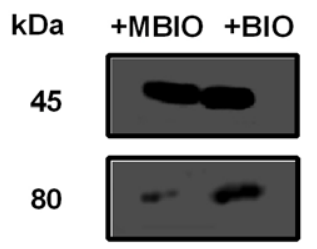

$+\mathrm{BIO}$

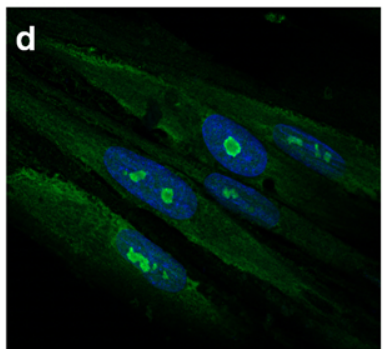

$\beta$-actin

N1ICD

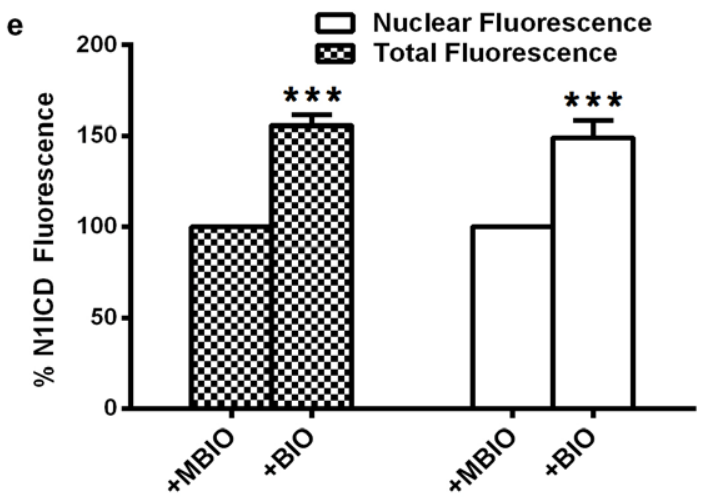

Fig. 6. Wnt activation by BIO positively regulated Notch signalling in DPSCs. (a) RT-PCR revealed differences in the expression of Notch mediators, ligands and receptors under BIO exposure. (b) qPCR analysis confirmed an increase in Notch 2, Jagged1, Wnt3, $\beta$-catenin and Hes1 expression between control (MBIO) and BIO conditions. Data were normalised to $\beta$-actin and Gapdh levels and presented as mean + SEM $(n=4)$. The dashed line represented normalised gene expression in control conditions. (c,d) IF images of active N1ICD, in cells treated with BIO and MBIO. Scale bar $=20 \mu \mathrm{m}$ (e) Bar chart showing relative total and nuclear N1ICD fluorescence in MBIO- and BIO-treated cells. (f) WB showing an increase in N1ICD expression in BIO-treated DPSCs. $\beta$-actin was used as a protein loading control. ${ }^{*} p<0.05$, ${ }^{* *} p<0.01,{ }^{* * *} p<0.001$. U-Mann Whitney test. 
Wnt/Notch activation enhanced expression of neural crest markers in DPSCs

Notch/Wnt are crucial in NC induction and their activation enhanced core factor expression in DPSCs. Thus, it was important to test whether NC markers would also be affected by Notch/Wnt pharmacological modulation. It was found that both Snai1 and Snai2 were constitutively expressed in DPSCs, especially Snail/Snail (Fig. 7a,b). Other NC gene markers, such as Pax3, Neurogenin2, Twist1 and $H n k 1$, were also expressed in control DPSCs. However, when DSPCs were cultured with DAPT, the expression of all these markers was downregulated to less than $50 \%$ of the basal levels as assessed by qPCR, with Pax3 being downregulated to more than $90 \%$ of its basal expression (Fig. 7a,b). Conversely, when cells were cultured with BIO, most markers showed a $\sim 2$-fold increased expression compared to control levels, with the notable exception of Pax3, which increased more than 10-fold (Fig. 7c,d). Some NC gene markers, which presented a very low expression in control DPSCs, such as Sox10, yielded consistent amplicon bands in conventional RT-PCR following $\mathrm{BIO}$ treatment. All these changes were corroborated by qPCR (Fig. 7c,d). Thus, Notch/Wnt activation upregulated the expression of both pluripotency and NC markers in DPSCs.

\section{Wnt/Notch pre-activation enhanced}

differentiation of DPSCs to osteoblasts and adipocytes

Several in vitro protocols can be used to induce terminal differentiation of DPSCs to mature osteoblasts and adipocytes (Gronthos et al., 2002; Langenbach and Handschel, 2013). The working hypothesis was that a short $(48 \mathrm{~h})$ pre-activation of the Notch/Wnt signalling pathway would render DPSCs more responsive to differentiation signals. Conversely, Notch/Wnt pre-inhibition would result in a reduced DPSC differentiation capacity. To test this hypothesis, DPSCs were exposed to BIO or DAPT for $48 \mathrm{~h}$. Untreated DPSCs were used a

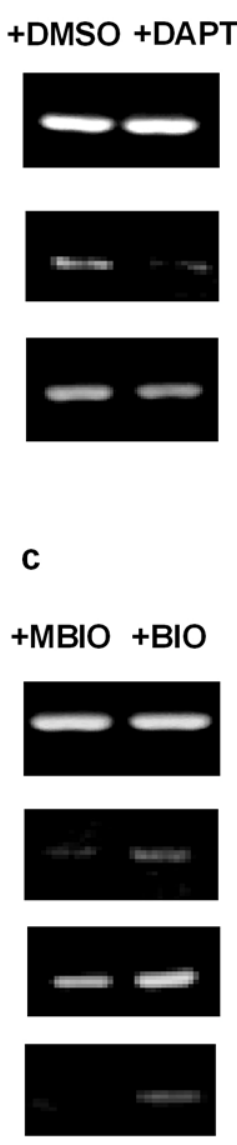

b

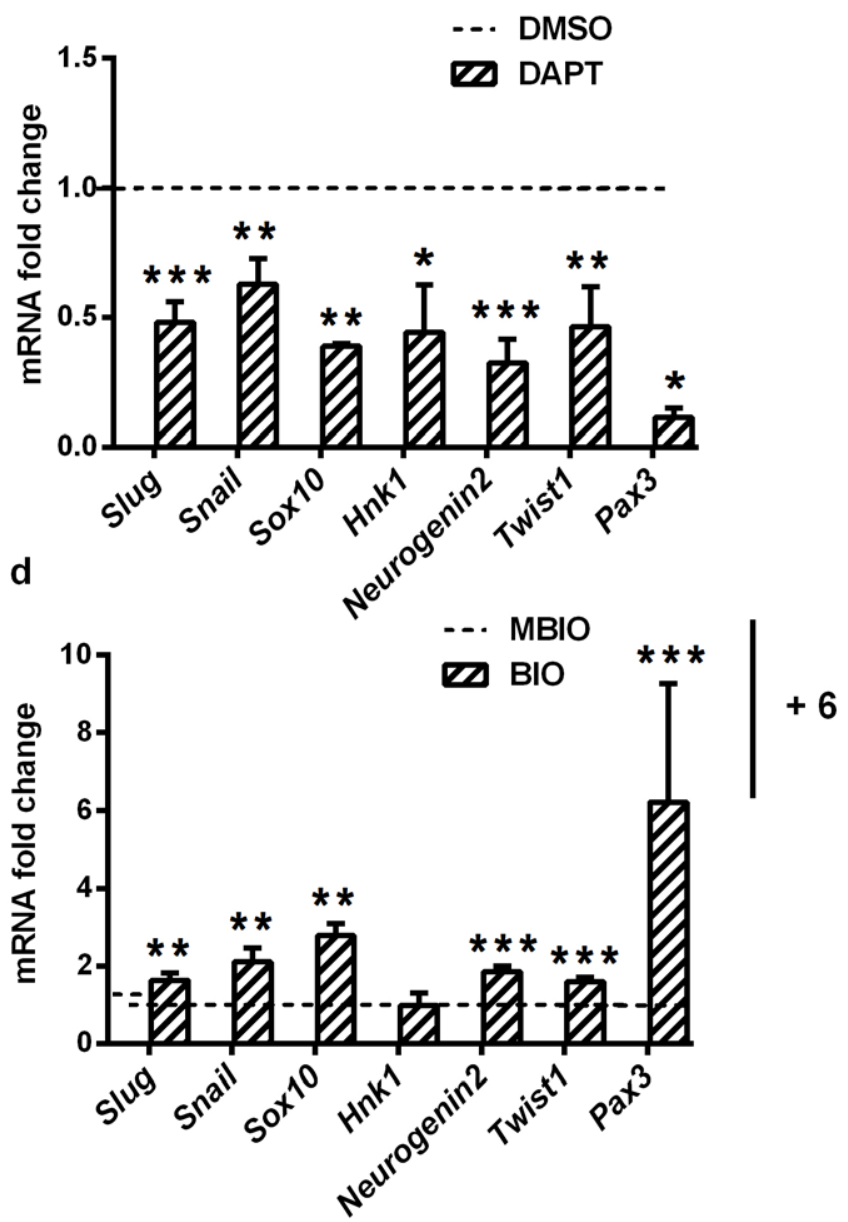

Fig. 7. BIO and DAPT antagonistically regulated the expression of NC markers Snail/Snai1, Slug/Snai2, Sox10, Hnk1, Neurogenin2, Twist and Pax3 in DPSCs. (a) RT-PCR showing NC marker gene expression in DMSO and DAPT-treated DPSCs. (b) qPCR showing relative differences on Snai1, Snai2, Sox10, Hnk1, Neurogenin2, Twist and Pax3 expression. (c) RT-PCR showing NC markers gene expression in MBIO and BIO-treated DPSCs. (d) qPCR showing relative differences in Snai1, Snai2, Sox10, Neurogenin2, Twist and Pax3 expression. Data were normalised to $\beta$-actin and Gapdh levels and represented as mean $+\operatorname{SEM}(n=3)$. The dashed line represented normalised gene expression in control conditions. ${ }^{*} p<0.05,{ }^{* *} p<0.01$, *** $p<0.001$. U-Mann Whitney test. 
as controls. Next, control and treated cells were exposed to osteoblastic differentiation medium in the absence of BIO or DAPT. To measure terminal osteoblastic differentiation, ALP and Alizarin Red $S$ assays were used. Interestingly, after 3 weeks of osteogenic treatment, Alizarin Red S staining and calcified matrix deposit formation, as assessed by light absorbance, were between two- and threefold higher in the DPSCs pre-treated with BIO and significantly lower in DPSCs pre-treated with
DAPT, when compared to controls (Fig. 8a-d,m). ALP enzymatic activity was also found to be significantly higher (i.e. osteoblastic differentiation more efficient) when DPSCs were pre-treated with BIO (Fig. 8e-h,m). To verify whether Notch/Wnt modulation could also affect DPSC differentiation into adipocytes, DPSCs were exposed to BIO or DAPT for $48 \mathrm{~h}$. Control and treated cells were then exposed to adipogenic differentiation medium for 4 weeks. Oil Red O staining was performed to assess

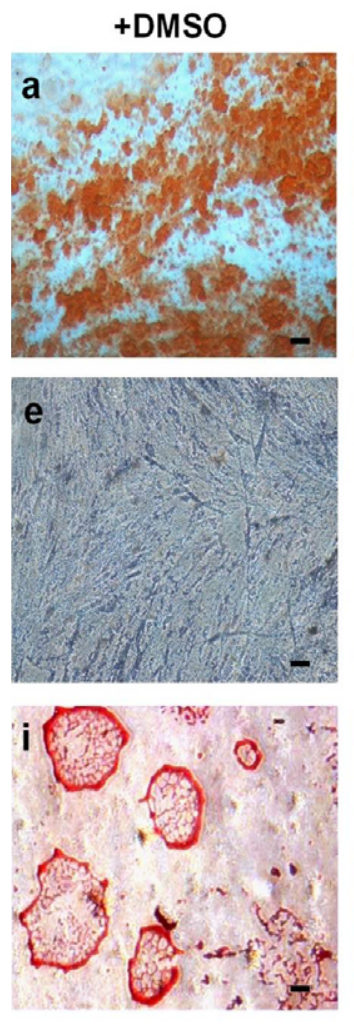

m
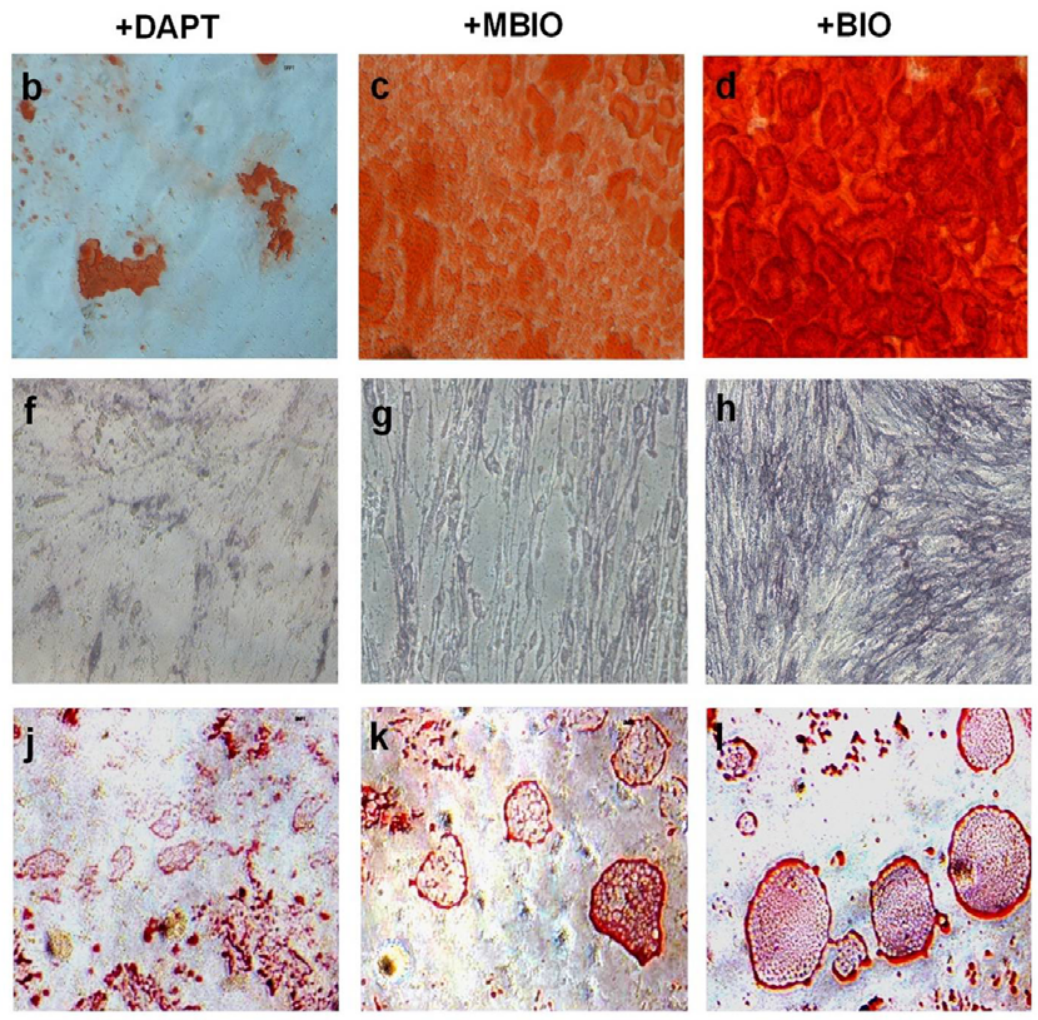

$\mathbf{n}$
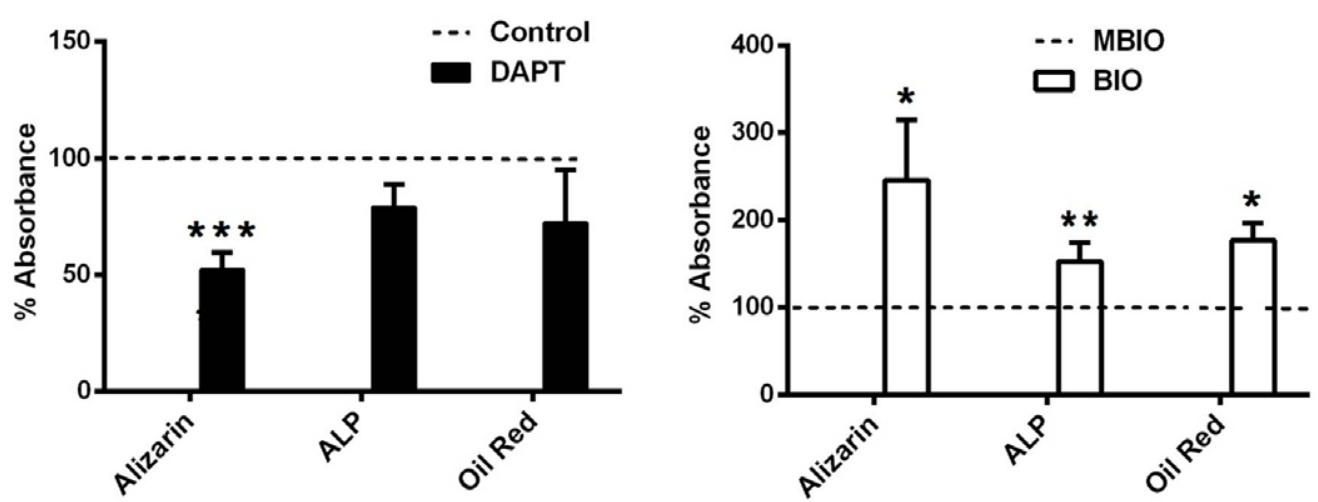

Fig. 8. A preconditioning exposure to BIO for $48 \mathrm{~h}$ enhanced DPSC differentiation efficiency into osteoblasts and adipocytes. (a-d) Alizarin Red S staining to assess calcified matrix formation and osteoblast differentiation in control (DMSO, MBIO), BIO and DAPT conditions. (e-h) ALP staining images at high magnification to detect osteoblastic commitment and differentiation in control (DMSO, MBIO), BIO and DAPT conditions. Scale bar $=100 \mu \mathrm{m}$. (i-1) Oil Red O staining to assess lipid droplet formation and adipocyte differentiation in control (DMSO, MBIO), BIO and DAPT conditions. Scale bar = $200 \mu \mathrm{m}$. (m) Relative absorbance quantification at $450 \mathrm{~nm}, 405 \mathrm{~nm}$ and $409 \mathrm{~nm}$ for Alizarin Red S, ALP and Oil Red O, respectively for DMSO- and DAPT-treated DPSCs. (n) Relative absorbance quantification at $450 \mathrm{~nm}$, $405 \mathrm{~nm}$ and $409 \mathrm{~nm}$ for Alizarin Red S, ALP and Oil Red O, respectively for MBIO and BIO conditions. Data were normalised to DMSO and MBIO as internal controls and presented as the mean $+\operatorname{SEM}(n=6)$. ${ }^{*} p<0.05,{ }^{* *} p<0.01,{ }^{* * *} p<0.001$. U-Mann Whitney test. 
adipocyte generation. Interestingly, it was found that BIO pre-treatment also enhanced DPSCs conversion to adipocytes as assessed by Oil Red $\mathrm{O}$ after the differentiation treatment period. Oil Red O staining was significantly higher in the BIO-pre-treated cells, near twice as much as controls (Fig. 8i-1,n).

Wnt activation by exposure to human recombinant Wnt-3a protein for $48 \mathrm{~h}$ enhanced the expression of $\mathrm{NC}$ and pluripotency core factors in DPSCs

Since BIO is known to be a general GSK3- $\beta$ inhibitor (Meijer et al., 2003), BIO treatment could affect other signalling pathways apart from Wnt. To prove that the observed effects on the expression of core and NC factors and stemness of DPSCs depended specifically on the canonical Wnt signalling pathway, Wnt-3a protein was used, a well-described prototypical canonical Wnt ligand (Famili et al., 2015; Zhang et al., 2009), to stimulate DPSCs for $48 \mathrm{~h}$ in similar conditions to $\mathrm{BIO}$ treatment. Two concentrations of human recombinant Wnt-3a were used: $2.5 \mu \mathrm{M}$ and $5 \mu \mathrm{M}$, to verify any possible dose-dependent effects. Interestingly, pluripotency and NC factors showed increased expression when exposed to Wnt-3a, being the effect more pronounced at the concentration of a

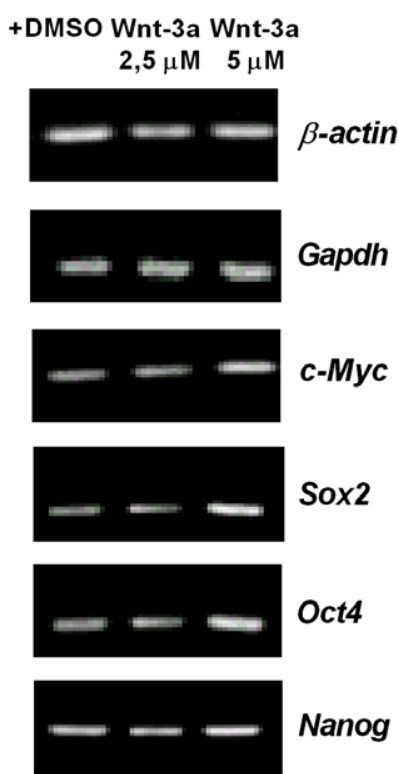

+DMSO Wnt-3a Wnt-3a $2,5 \mu \mathrm{M} \quad 5 \mu \mathrm{M}$
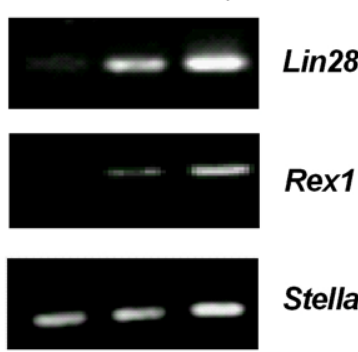

Stella

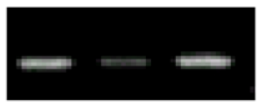

Ssea1

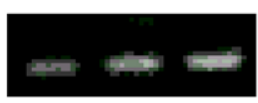

$\beta$-catenin

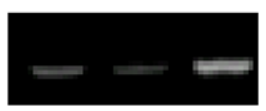

Hes1
+DMSO Wnt-3a Wnt-3a $2,5 \mu \mathrm{M} \quad 5 \mu \mathrm{M}$
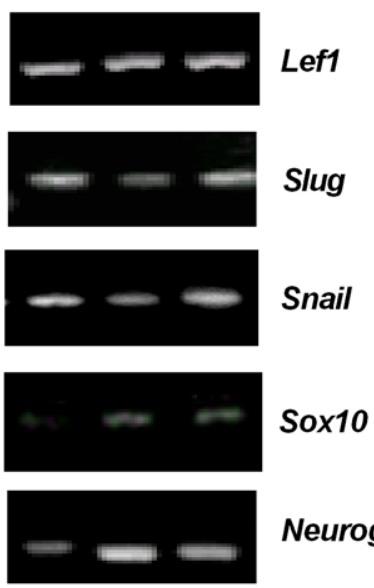

Neurogenin2

Pax3
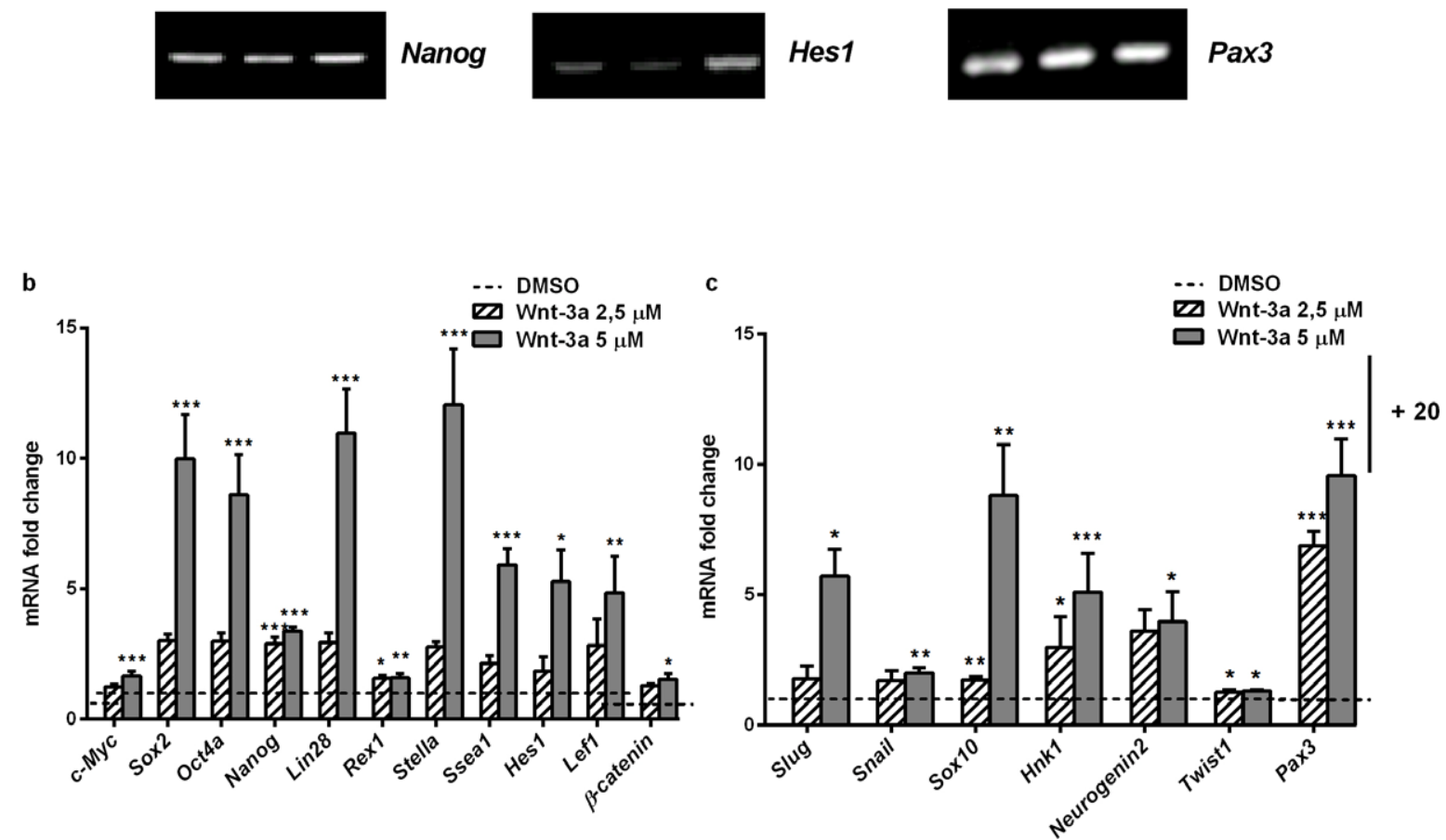

Fig. 9. Wnt activation by Wnt-3a increased the expression of pluripotency core factors, Notch markers and NC markers in DPSCs. (a) RT-PCR showing core factors (c-Myc, Sox2, Nanog, Oct4, Rex1, Stella and Ssea1), Hes1 and NC markers (Snai1, Snai2, Sox10, Hnk1, Neurogenin2, Twist and Pax3) expression in DPSCs treated with DMSO and $2.5 \mu \mathrm{M}$ and $5 \mu \mathrm{M}$ Wnt-3a.(b,c) qPCR showing relative differences in the expression of (b) the core factors c-Myc, Sox2, Nanog, Oct4, Rex1, Stella, Ssea1, Hes1, Lef1 and $\beta$-catenin and (c) the NC markers Snai1, Snai2, Sox10, Hnk1, Neurogenin2, Twist and Pax3. Data were normalised to $\beta$-actin and Gapdh levels and represented as the mean + SEM $(n=3)$. The dashed line represented normalised gene expression in control conditions. ${ }^{*} p<0.05,{ }^{* *} p<0.01,{ }^{* *} p<0.005$. Dunn's Test, Kruskall Wallis H Test. 
$5 \mu \mathrm{M}$. Among the markers that were most strongly affected Sox2, Oct4 (Pou5f1 and Pou5f1p1), Lin28, Stella, Ssea1, Slug, Hnk1 and Sox10 were detected (all within a $\sim 5-10$-fold increase in expression) Pax3 was also present ( 30-fold increase with $5 \mu \mathrm{M}$ Wnt3a). As a control for Wnt activation, Lef1 expression was solidly upregulated after Wnt-3a treatment. All expression changes were verified by RT-PCR and qPCR (Fig. 9a-c).

\section{Exposure to Wnt-3a upregulated Notch/Wnt} crosstalk signalling in DPSCs

Verification whether the Notch/Wnt interaction was also required, which was observed after DAPT/BIO treatments, and was also observed after treating cells with Wnt-3a. QPCR experiments had already showed a clear upregulation of Hes1 expression in
DPSCs exposed to Wnt-3a (Fig. 9b). This result was corroborated by IF and a significantly increased N1ICD nuclear fluorescence was found, especially at a concentration of $5 \mu \mathrm{M}$ Wnt-3a (Fig. 10a-c,k). Similarly, nuclear $\beta$-catenin protein labelling was also found to be increased (Fig. 10d-f,k). Finally, similar results were observed for Ki67 labelling levels (Fig. $10 \mathbf{g}-\mathbf{I}, \mathbf{k})$. Thus, $5 \mu \mathrm{M}$ Wnt-3a induced a coordinated upregulation of Notch/Wnt cross-signalling and an increased proliferation capacity in DPSCs.

\section{A preconditioning treatment with human} recombinant Wnt-3a enhanced the differentiation capacity of DPSCs to osteoblasts and adipocytes Finally, and in view of the previous results, verification was needed as to whether a preconditioning treatment with Wnt-3a would also render DPSCs
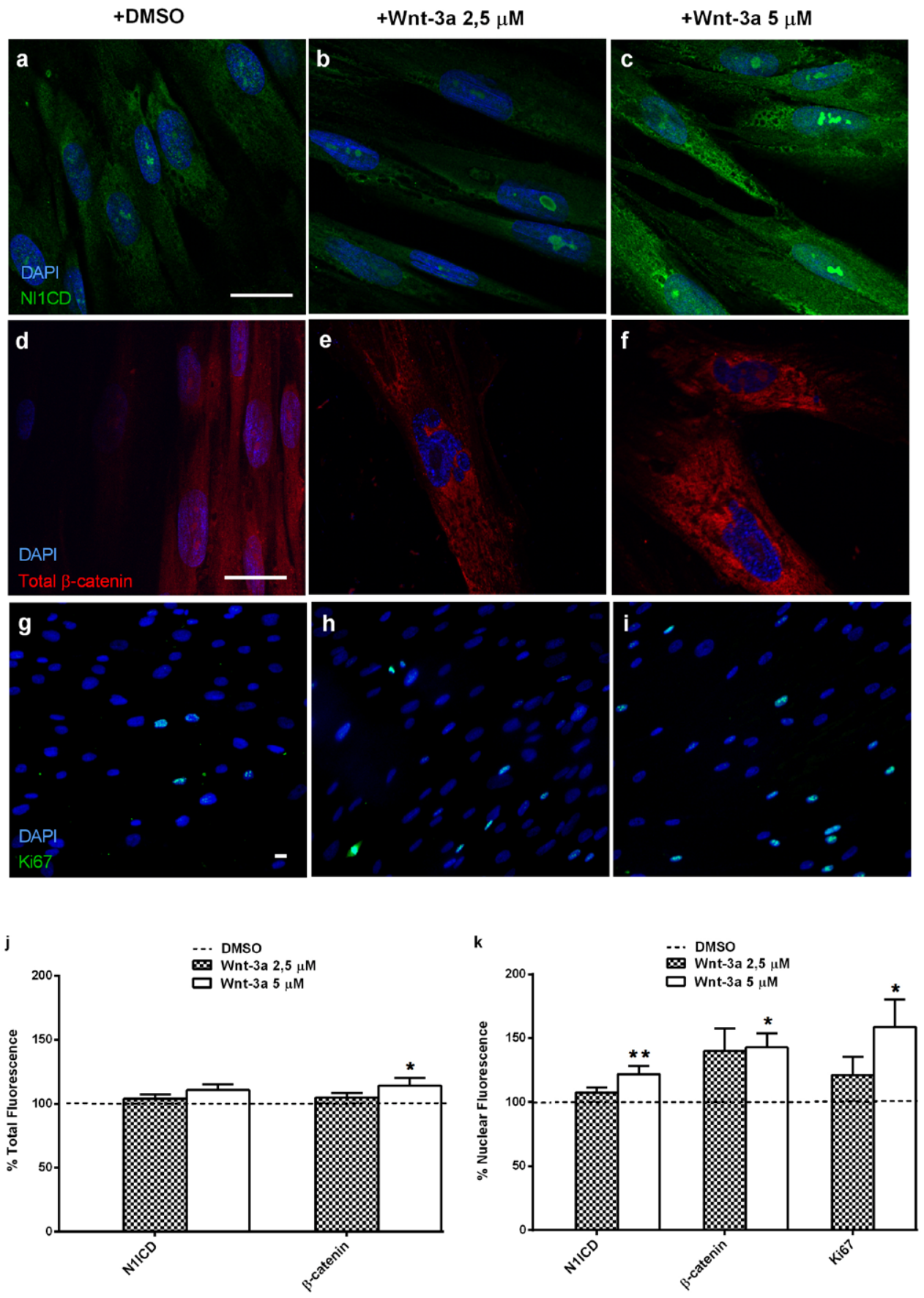

Fig. 10. Wnt activation by Wnt-3a upregulated Notch signalling in DPSCs. (a-i) IF images of DPSCs grown for $48 \mathrm{~h}$ in presence or absence of Wnt$3 a$ at two different concentrations of $2.5 \mu \mathrm{M}$ and $5 \mu \mathrm{M}$ and immunolabeled for (a-c) N1ICD, (d-f) total $\beta$-catenin (g-i) and Ki67. DAPI labelled cell nuclei in blue. Scale bar $=20 \mu \mathrm{m}$. (j) Bar charts showing relative total N1ICD and total $\beta$-catenin fluorescence in control and Wnt-3a-treated DPSCs. (k) Bar charts showing relative nuclear N1ICD, $\beta$-catenin and $\mathrm{Ki} 67$ labelling fluorescence in control and Wnt-3atreated DPSCs. Data are presented as mean $+\operatorname{SEM}(n=3) .{ }^{*} p<0.05$, ** $p<0.01, * * * p<0.001$. Dunn's Test, Kruskall Wallis H Test. 
more responsive to osteogenic and adipogenic differentiation treatments. DPSCs were exposed to a preconditioning treatment with Wnt-3a for $48 \mathrm{~h}$ and subsequently cells were placed in osteogenic and adipogenic culture media, respectively - in similar conditions as shown before with DAPT/BIO. As predicted, pre-treatment with Wnt-3a enhanced the capacity of DPSCs to differentiate to osteoblasts and adipocytes (Fig. 11). The effect was more pronounced with $5 \mu \mathrm{M}$ than with $2.5 \mu \mathrm{M}$ Wnt-3a and was comparable to the one obtained with BIO (Fig. 8), with an almost 3-fold increase in Alizarin Red $S$ staining and near to 2-fold increase in Oil Red O staining compared to control, non-pre-treated DPSCs cultures (Fig. 11j).

\section{Discussion}

It was here reported for the first time that both Notch and Wnt signalling were required for the expression of NC and pluripotency core factors in DPSCs. Importantly, both pathways positively regulated each other in maintaining DPSC stemness and specific activation or inhibition of one pathway invariably affected the other in the same way. These findings shed light on the control mechanisms of DPSC self-renewal and maintenance and have important potential implications regarding the use of DPSCs for cell therapy.

There are several reasons for the interest in DPSCs and other dental stem cells. These cells are easily
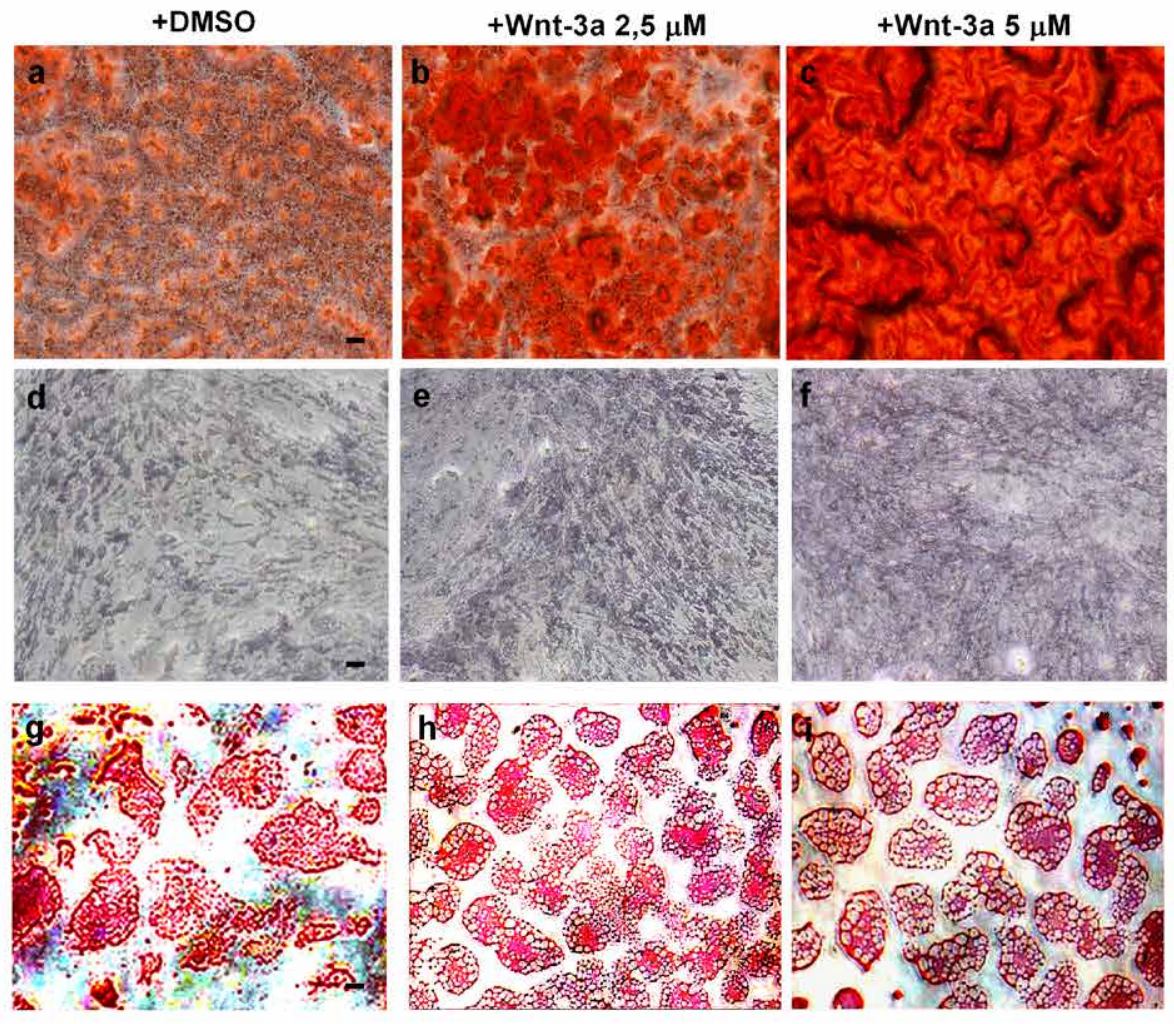

j
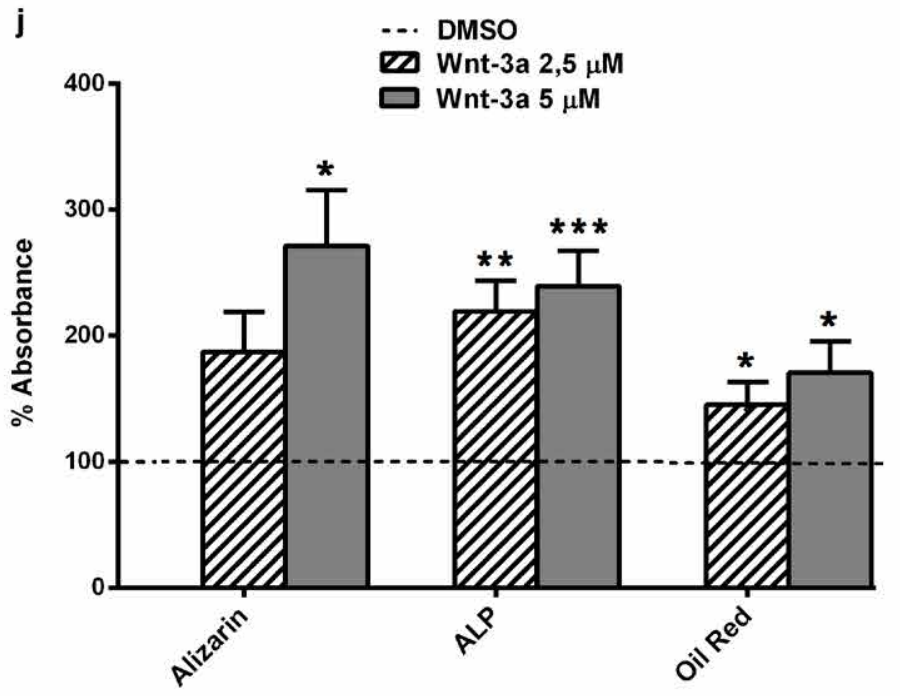

Fig. 11. A preconditioning treatment with Wnt3a for $48 \mathrm{~h}$ enhanced DPSC differentiation efficiency into osteoblasts and adipocytes. (a-c) Alizarin Red S staining to assess calcified matrix formation and osteoblast differentiation in control (DMSO) and Wnt-3a $(2.5 \mu \mathrm{M}$ and $5 \mu \mathrm{M}$ ) conditions. (df) ALP staining images at high magnification to detect osteoblastic lineage commitment and differentiation in control (DMSO) and Wnt3a $(2.5 \mu \mathrm{M}$ and $5 \mu \mathrm{M})$ conditions. (g-i) Oil Red $\mathrm{O}$ staining to assess lipid droplet formation and adipocyte differentiation in control (DMSO) and Wnt-3a $(2.5 \mu \mathrm{M}$ and $5 \mu \mathrm{M})$ treatment. Scale bar $=200 \mu \mathrm{m}$ (j) Relative absorbance quantification at $450 \mathrm{~nm}, 405 \mathrm{~nm}$ and $409 \mathrm{~nm}$ for Alizarin Red $\mathrm{S}$, ALP and Oil Red O, respectively. Data were normalised to DMSO as internal control and presented as mean + SEM $(n=4) .{ }^{*} p<0.05$. Dunn's Test, Kruskall Wallis H Test. 
accessible in both young and aged patients, possess a significant capacity for in vitro expansion and have non-tumourigenic phenotypes. Furthermore, evidence shows that DPSCs have a greater multilineage differentiation potential compared to other tissue-specific stem cells (Atari et al., 2012; Kerkis et al., 2006; Rosa et al., 2016). It is illustrative of the growing acknowledgement of the stemness potential of DPSCs that some authors have referred to some subpopulations of these cells as dental pulp pluripotent stem cells or DPPSCs (Atari et al., 2012).

Arguably, induced pluripotent stem cells (iPSCs), derived from autologous somatic cells, could be regarded as the ideal source of stem cells for in vivo cell therapy. These cells are truly pluripotent (i.e. have no restriction to differentiate in any type of adult cell), can be extracted from any donor's tissue and have the donor's same genetic background. However, traditional cell reprogramming procedures rely on permanent gene transfection with Yamanaka or related core pluripotency factors (Takahashi et al., 2007) and, for safety reasons, this is not yet acceptable. Hence, while these cell reprogramming technologies are not mature enough for clinical use, the interest in searching for alternative sources of autologous pluripotent-like cells, including DPSCs, is growing very fast. The possibility to boost the natural pluripotency-like features of DPSCs by methods that do not involve permanent chromatin modification or gene transfection is highly desirable for cell therapy.

Canonical Notch and Wnt signalling pathways are described as pivotal regulators of stemness and pluripotency (Clevers et al., 2014; Dravid et al., 2005; Fox et al., 2008; Li and Chen, 2012; Lluis et al., 2008; Lowell et al., 2006; Park et al., 2008; Simandi et al., 2016; Yan et al., 2010) and their pharmacological manipulation has already been tested as a strategy to enhance either cell differentiation (Kitajima et al., 2016) or cell reprogramming (Ichida et al., 2014). Notch inhibition by $\gamma$-secretase blockers is associated with an increased efficiency of keratinocyte reprogramming (Ichida et al., 2014). However, a very different effect was found in the studied model system with DCPSs: Notch inhibition by DAPT decreased the expression of core factors in DPSCs and diminished their capacity to generate fully differentiated osteoblasts and adipocytes. In this regard, it was worthy to note that Notch effects have long been known to be extremely context-dependent: the same Notch signal can have very different outcomes depending on the cell type, physiological state and extracellular environment. Regarding Wnt signalling, its pharmacological activation by GSK3- $\beta$ inhibitors in mouse iPSCs is associated with increased cell differentiation (Kitajima et al., 2016). However, in the DPSC model, BIO application significantly increased the expression of core factors and enhanced DPSC differentiation potential towards adult osteoblasts and adipocytes. Again, these differences were attributed to the different cell culture systems that were tested in this and other studies.
One important difference between the current study and the aforementioned studies was the presence/absence of serum in the culture medium. The use of medium containing FBS is well established as the gold standard for manipulation and in vitro expansion of DPSCs (Gronthos et al., 2002; Gronthos et al., 2000). In vitro expansion of DPSCs is often inevitable due to the small amounts of tissue material and total cell numbers that can be collected from the human dental pulp, as compared to other stem cell sources. In this regard, despite ongoing progress in culture media formulations that do not contain foetal serum for maintenance of DPSCs (Bonnamain et al., 2013; Eubanks et al., 2014; Jung et al., 2016; Xiao and Tsutsui, 2013), currently the addition of FBS or related agents to the culture media permits easily overcoming the issue of initial cell expansion. However, it is becoming increasingly apparent that FBS-containing media also induce differentiation of DPSCs into a default osteo/odontogenic pathway (Pisciotta et al., 2012; Yu et al., 2010) and this may not be the best choice to generate certain cell lineages, particularly neural cells, from DPSCs (Jung et al., 2016). Moreover, upon continual expansion induced by the presence of $10 \%$ FBS, DPSC cultures also tend to generate populations of committed/differentiated cells (Mokry et al., 2010). Therefore, progressive stem cell exhaustion was also a concern in this study. We confirmed that the proliferation rates and core factor expression decreased steadily in DPSCs upon serial passaging (data not shown). This correlation between sustained stem cell aging and loss of multipotency is also reported elsewhere (Bose and Shenoy, 2016).

One important finding of this study was that Notch and Wnt pathways operated coordinately as part of a common network to maintain DPSC stemness. We found that the expression of core factors in DPSCs was completely dependent upon Notch/Wnt signalling. Notch inhibition by DAPT applications abolished the expression of core factors and decreased DPSC stemness. These results were accompanied by parallel Wnt inhibition. Conversely, Wnt activation by BIO or Wnt-3a significantly increased the expression of core factors and DPSC stemness. In view of this evidence, the question became what connection do these pathways have at the molecular level? Many positive and negative interactions are reported between both pathways in a myriad of model systems (Borggrefe et al., 2016; Fukunaga-Kalabis et al., 2015; Kwon et al., 2011; Nicolas et al., 2003; Shi et al., 2015). In colorectal cancer cells, Wnt signalling affects Notch through $\beta$-catenin-mediated transcriptional activation of the gene Jagged1 (Rodilla et al., 2009). Jagged1 is a Notch ligand, which can activate Notch receptors and, consequently, Notch signalling. Consistently, BIOinduced Wnt activation in DPSC elicited a sharp increase in the transcriptional levels of Jagged1. It is likely that such an increased Jagged1 transcription would eventually activate Notch receptors in DPSCs cultures. In addition, $\beta$-catenin physically binds to and interacts with reprogramming factors, in 
particular Oct4a (Simandi et al., 2016), whereas Oct4a transcription levels are also positively regulated by Wnt signalling in pluripotent stem cells ( $\mathrm{Li}$ and Chen, 2012; Simandi et al., 2016). Finally, Wnt/ $\beta$-catenin also increases $c-M y c$ transcription, which promotes cell proliferation (Barker et al., 2000). Consistently, DPSCs treated with BIO or Wnt-3a showed an increased transcription of $c-M y c$, which was related to an increased cell proliferation.

Together with enhanced core factor expression, activation of the Notch/Wnt signalling pathways also increased the expression of NC markers in DPSCs. Both Notch and Wnt signals are associated with NC induction (Gazarian and Ramirez-Garcia, 2017; Hari et al., 2012; Leung et al., 2016; Rogers et al., 2012; Stuhlmiller and Garcia-Castro, 2012). Indeed, NC cells also express relatively high levels of core factors, which possibly relates to their ample capacity to generate very diverse cell lineages (Thomas et al., 2008). It was found that the NC markers Pax3, Hnk1, Twist, Neurogenin2, Snail/Snai1, Slug/Snai2 and Sox10 had increased expression levels when the DPSCs were exposed to Wnt-3a or BIO and that their expression decreased in the presence of DAPT, thus showing a similar relationship to the one found with pluripotency core factors.

The results demonstrated that Wnt/Notch activation increased DPSC stemness. This could have important implications for optimising the clinical use of these cells. A short preconditioning treatment with Wnt-3a or BIO for $48 \mathrm{~h}$ was enough to improve the potential of DPSC to differentiate into at least two different adult cell lineages, osteoblasts and adipocytes, which are both of mesenchymal origin. This very important finding proved that DPSC exhaustion by continuous exposure to FBS could be at least partially prevented by transiently boosting the activity of Notch/Wnt pathways, by means of small molecules and/or recombinant proteins, which would enhance stemness traits of DPSC cultures just $48 \mathrm{~h}$ before use for differentiation or cell transplant. It would also be very interesting to verify whether such preconditioning would also be effective for other non-mesenchymal cell lineages of interest, such as Schwann cells (Martens et al., 2014), neuron-like cells (Gervois et al., 2015) and hepatocyte-like cells (Atari et al., 2012). Finally, the adoption of this preconditioning strategy could also be applicable to differentiation protocols that do not rely on FBS (Eubanks et al., 2014; Xiao and Tsutsui, 2013), allowing for a faster translation to clinical therapy.

\section{Conclusions}

Our data showed that Notch and Wnt signalling were required for the maintenance of $\mathrm{NC}$ and core pluripotency factor expression in DPSCs. Furthermore, both pathways operated coordinately as part of the same signalling network to maintain DPSC stemness. Thus, a 48 h Notch/Wnt signalling activation preconditioning step by $\mathrm{BIO}$ or Wnt-3a significantly enhanced the capacity of DPSCs to respond to standard in vitro protocols for osteoblastic and adipogenic differentiation. Conversely, Notch/ Wnt inhibition decreased DPSC stemness. These preconditioning changes involved levels of expression of core pluripotency and NC factors, which correlated with an enhanced differentiation potential of DPSCs. This strategy could be used alone or in conjunction with other cell reprogramming methods that do not involve permanent gene transduction or modifications at genome level to generate DPSCs and other tissue-specific adult stem cells with increased self-renewal and cell differentiation potential for cell therapy.

\section{Acknowledgements}

Technical and human support provided by the analytical microscopy service of SGIKER (UPV/ EHU, MINECO, GV/EJ, ERDF and ESF) is gratefully acknowledged. This work was funded by the UPV/EHU (GIU16/66, UFI 11/44) and the Basque Government (GV/EJ; IT831-13). V.U. received a fellowship from The Global Training Grant (GV/EJ) to fund a research stage at The Institute of Cancer Research (London, UK).

\section{References}

Abe S, Hamada K, Miura M, Yamaguchi S (2012) Neural crest stem cell property of apical pulp cells derived from human developing tooth. Cell Biol Int 36: 927-936.

Androutsellis-Theotokis A, Leker RR, Soldner F, Hoeppner DJ, Ravin R, Poser SW, Rueger MA, Bae SK, Kittappa R, McKay RD (2006) Notch signalling regulates stem cell numbers in vitro and in vivo. Nature 442: 823-826.

Atari M, Barajas M, Hernandez-Alfaro F, Gil C, Fabregat M, Ferres Padro E, Giner L, Casals N (2011) Isolation of pluripotent stem cells from human third molar dental pulp. Histol histopathol 26: 1057-1070.

Atari M, Gil-Recio C, Fabregat M, GarciaFernandez D, Barajas M, Carrasco MA, Jung HS, Alfaro FH, Casals N, Prosper F, Ferres-Padro E, Giner L (2012) Dental pulp of the third molar: a new source of pluripotent-like stem cells. J Cell Sci 125: 3343-3356.

Atlasi Y, Mowla SJ, Ziaee SA, Gokhale PJ, Andrews PW (2008) OCT4 spliced variants are differentially expressed in human pluripotent and nonpluripotent cells. Stem Cells 26: 3068-3074.

Aurrekoetxea M, Garcia-Gallastegui P, Irastorza I, Luzuriaga J, Uribe-Etxebarria V, Unda F, Ibarretxe G (2015) Dental pulp stem cells as a multifaceted tool for bioengineering and the regeneration of craniomaxillofacial tissues. Front Physiol 6: 289. 
Barker N, Morin PJ, Clevers H (2000) The Yin-Yang of TCF/beta-catenin signaling. Adv Cancer Res 77: $1-24$.

Bonnamain V, Thinard R, Sergent-Tanguy S, Huet P, Bienvenu G, Naveilhan P, Farges JC, Alliot-Licht B (2013) Human dental pulp stem cells cultured in serum-free supplemented medium. Front Physiol 4: 357.

Borggrefe T, Lauth M, Zwijsen A, Huylebroeck D, Oswald F, Giaimo BD (2016) The Notch intracellular domain integrates signals from Wnt, Hedgehog, TGFbeta/BMP and hypoxia pathways. Biochim Biophys Acta 1863: 303-313.

Borghese L, Dolezalova D, Opitz T, Haupt S, Leinhaas A, Steinfarz B, Koch P, Edenhofer F, Hampl A, Brustle $O$ (2010) Inhibition of notch signaling in human embryonic stem cell-derived neural stem cells delays G1/S phase transition and accelerates neuronal differentiation in vitro and in vivo. Stem Cells 28: 955964.

Bose B, Shenoy PS (2016) Pluripotent conversion of muscle stem cells without reprogramming factors or small molecules. Stem Cell Rev 12: 73-89.

Chambers I, Tomlinson SR (2009) The transcriptional foundation of pluripotency. Development 136: 2311-2322.

Clevers H (2006) Wnt/beta-catenin signaling in development and disease. Cell 127: 469-480.

Clevers H, Loh KM, Nusse R (2014) Stem cell signaling. An integral program for tissue renewal and regeneration: Wnt signaling and stem cell control. Science 346: 1248012.

D'Souza B, Meloty-Kapella L, Weinmaster G (2010) Canonical and non-canonical Notch ligands. Curr Top Dev Biol 92: 73-129.

Dravid G, Ye Z, Hammond H, Chen G, Pyle A, Donovan P, Yu X, Cheng L (2005) Defining the role of Wnt/beta-catenin signaling in the survival, proliferation, and self-renewal of human embryonic stem cells. Stem Cells 23: 1489-1501.

Eubanks EJ, Tarle SA, Kaigler D (2014) Tooth storage, dental pulp stem cell isolation, and clinical scale expansion without animal serum. J Endod 40: 652-657.

Famili F, Naber BA, Vloemans S, de Haas EF, Tiemessen MM, Staal FJ (2015) Discrete roles of canonical and non-canonical Wnt signaling in hematopoiesis and lymphopoiesis. Cell Death Dis 6: e1981.

Ferro F, Spelat R, D'Aurizio F, Puppato E, Pandolfi M, Beltrami AP, Cesselli D, Falini G, Beltrami CA, Curcio F (2012) Dental pulp stem cells differentiation reveals new insights in Oct4A dynamics. PloS One 7: e41774.

Fox V, Gokhale PJ, Walsh JR, Matin M, Jones M, Andrews PW (2008) Cell-cell signaling through $\mathrm{NOTCH}$ regulates human embryonic stem cell proliferation. Stem Cells 26: 715-723.

Fukunaga-Kalabis M, Hristova DM, Wang JX, Li L, Heppt MV, Wei Z, Gyurdieva A, Webster MR,
Oka M, Weeraratna AT, Herlyn M (2015) UV-Induced Wnt7a in the human skin microenvironment specifies the fate of neural crest-like cells via suppression of Notch. J Invest Dermatol 135: 1521-1532.

Gazarian KG, Ramirez-Garcia LR (2017) Human deciduous teeth stem cells (SHED) display neural crest signature characters. PloS One 12: e0170321.

Gervois P, Struys T, Hilkens P, Bronckaers A, Ratajczak J, Politis C, Brone B, Lambrichts I, Martens W (2015) Neurogenic maturation of human dental pulp stem cells following neurosphere generation induces morphological and electrophysiological characteristics of functional neurons. Stem Cells Dev 24: 296-311.

Gronthos S, Brahim J, Li W, Fisher LW, Cherman N, Boyde A, DenBesten P, Robey PG, Shi S (2002) Stem cell properties of human dental pulp stem cells. J Dent Res 81: 531-535.

Gronthos S, Mankani M, Brahim J, Robey PG, Shi S (2000) Postnatal human dental pulp stem cells (DPSCs) in vitro and in vivo. Proc Natl Acad Sci U S A 97: 13625-13630.

Hari L, Miescher I, Shakhova O, Suter U, Chin L, Taketo M, Richardson WD, Kessaris N, Sommer L (2012) Temporal control of neural crest lineage generation by Wnt/beta-catenin signaling. Development 139: 2107-2117.

Huang GT, Gronthos S, Shi S (2009) Mesenchymal stem cells derived from dental tissues vs. those from other sources: their biology and role in regenerative medicine. J Dent Res 88: 792-806.

Ibarretxe G, Crende O, Aurrekoetxea M, GarciaMurga V, Etxaniz J, Unda F (2012) Neural crest stem cells from dental tissues: a new hope for dental and neural regeneration. Stem Cells Int 2012: 103503.

Ichida JK, Tcw J, Williams LA, Carter AC, Shi Y, Moura MT, Ziller M, Singh S, Amabile G, Bock C, Umezawa A, Rubin LL, Bradner JE, Akutsu H, Meissner A, Eggan K (2014) Notch inhibition allows oncogene-independent generation of iPS cells. Nat Chem Biol 10: 632-639.

Janebodin K, Horst OV, Ieronimakis N, Balasundaram G, Reesukumal K, Pratumvinit B, Reyes M (2011) Isolation and characterization of neural crest-derived stem cells from dental pulp of neonatal mice. PloS One 6: e27526.

Jung J, Kim JW, Moon HJ, Hong JY, Hyun JK (2016) Characterization of neurogenic potential of dental pulp stem cells cultured in xeno/serum-free condition: in vitro and in vivo assessment. Stem Cells Int 2016: 6921097.

Kaukua N, Shahidi MK, Konstantinidou C, Dyachuk V, Kaucka M, Furlan A, An Z, Wang L, Hultman I, Ahrlund-Richter L, Blom H, Brismar H, Lopes NA, Pachnis V, Suter U, Clevers H, Thesleff I, Sharpe P, Ernfors P, Fried K, Adameyko I (2014) Glial origin of mesenchymal stem cells in a tooth model system. Nature 513: 551-554.

Kellner M, Steindorff MM, Strempel JF, Winkel A, Kuhnel MP, Stiesch M (2014) Differences of 
isolated dental stem cells dependent on donor age and consequences for autologous tooth replacement. Arch Oral Biol 59: 559-567.

Kerkis I, Kerkis A, Dozortsev D, Stukart-Parsons GC, Gomes Massironi SM, Pereira LV, Caplan AI, Cerruti HF (2006) Isolation and characterization of a population of immature dental pulp stem cells expressing OCT-4 and other embryonic stem cell markers. Cells Tissues Organs 184: 105-116.

Kiraly M, Porcsalmy B, Pataki A, Kadar K, Jelitai M, Molnar B, Hermann P, Gera I, Grimm WD, Ganss B, Zsembery A, Varga G (2009) Simultaneous PKC and cAMP activation induces differentiation of human dental pulp stem cells into functionally active neurons. Neurochem Int 55: 323-332.

Kitajima K, Nakajima M, Kanokoda M, Kyba M, Dandapat A, Tolar J, Saito MK, Toyoda M, Umezawa A, Hara T (2016) GSK3beta inhibition activates the CDX/HOX pathway and promotes hemogenic endothelial progenitor differentiation from human pluripotent stem cells. Exp Hematol 44: 68-74.e61-10.

Kwon C, Cheng P, King IN, Andersen P, Shenje L, Nigam V, Srivastava D (2011) Notch posttranslationally regulates beta-catenin protein in stem and progenitor cells. Nat Cell Biol 13: 1244-1251.

Langenbach F, Handschel J (2013) Effects of dexamethasone, ascorbic acid and betaglycerophosphate on the osteogenic differentiation of stem cells in vitro. Stem Cell Res Ther 4: 117.

Leung AW, Murdoch B, Salem AF, Prasad MS, Gomez GA, Garcia-Castro MI (2016) WNT/betacatenin signaling mediates human neural crest induction via a pre-neural border intermediate. Development 143: 398-410.

Li J, Chen B (2012) Oct4 was a novel target of Wnt signaling pathway. Mol Cell Biochem 362: 233-240.

Liedtke S, Enczmann J, Waclawczyk S, Wernet $P$, Kogler G (2007) Oct4 and its pseudogenes confuse stem cell research. Cell Stem Cell 1: 364-366.

Lima RL, Holanda-Afonso RC, Moura-Neto V, Bolognese AM, DosSantos MF, Souza MM (2017) Human dental follicle cells express embryonic, mesenchymal and neural stem cells markers. Arch Oral Biol 73: 121-128.

Liu J, Yu F, Sun Y, Jiang B, Zhang W, Yang J, Xu GT, Liang A, Liu S (2015) Concise reviews: Characteristics and potential applications of human dental tissuederived mesenchymal stem cells. Stem Cells 33: 627638.

Livak KJ, Schmittgen TD (2001) Analysis of relative gene expression data using real-time quantitative PCR and the 2(-delta delta C(T)) method. Methods 25: 402-408.

Lluis F, Pedone E, Pepe S, Cosma MP (2008) Periodic activation of Wnt/beta-catenin signaling enhances somatic cell reprogramming mediated by cell fusion. Cell Stem Cell 3: 493-507.

Lowell S, Benchoua A, Heavey B, Smith AG (2006) Notch promotes neural lineage entry by pluripotent embryonic stem cells. PLoS Biol 4: e121.
Marrelli M, Paduano F, Tatullo M (2013) Cells isolated from human periapical cysts express mesenchymal stem cell-like properties. Int J Biol Sci 9: 1070-1078.

Marrelli M, Paduano F, Tatullo M (2015) Human periapical cyst-mesenchymal stem cells differentiate into neuronal cells. J Dent Res 94: 843-852.

Martens W, Sanen K, Georgiou M, Struys T, Bronckaers A, Ameloot M, Phillips J, Lambrichts I (2014) Human dental pulp stem cells can differentiate into Schwann cells and promote and guide neurite outgrowth in an aligned tissue-engineered collagen construct in vitro. FASEB J 28: 1634-1643.

Meijer L, Skaltsounis AL, Magiatis P, Polychronopoulos P, Knockaert M, Leost M, Ryan XP, Vonica CA, Brivanlou A, Dajani R, Crovace C, Tarricone C, Musacchio A, Roe SM, Pearl L, Greengard P (2003) GSK-3-selective inhibitors derived from Tyrian purple indirubins. Chem Biol 12: 1255-1266.

Mizutani K, Yoon K, Dang L, Tokunaga A, Gaiano N (2007) Differential Notch signalling distinguishes neural stem cells from intermediate progenitors. Nature 449: 351-355.

Mokry J, Soukup T, Micuda S, Karbanova J, Visek B, Brcakova E, Suchanek J, Bouchal J, Vokurkova D, Ivancakova R (2010) Telomere attrition occurs during ex vivo expansion of human dental pulp stem cells. J Biomed Biotechnol 2010: 673513.

Nicolas M, Wolfer A, Raj K, Kummer JA, Mill P, van Noort M, Hui CC, Clevers H, Dotto GP, Radtke F (2003) Notch1 functions as a tumor suppressor in mouse skin. Nat Genet 33: 416-421.

Park IH, Zhao R, West JA, Yabuuchi A, Huo $\mathrm{H}$, Ince TA, Lerou PH, Lensch MW, Daley GQ (2008) Reprogramming of human somatic cells to pluripotency with defined factors. Nature 451: 141146.

Perdigoto CN, Bardin AJ (2013) Sending the right signal: Notch and stem cells. Biochim Biophys Acta 1830: 2307-2322.

Petrovic V, Stefanovic V (2009) Dental tissue - new source for stem cells. TheScientificWorldJournal 9: 1167-1177.

Pierdomenico L, Bonsi L, Calvitti M, Rondelli D, Arpinati M, Chirumbolo G, Becchetti E, Marchionni C, Alviano F, Fossati V, Staffolani N, Franchina M, Grossi A, Bagnara GP (2005) Multipotent mesenchymal stem cells with immunosuppressive activity can be easily isolated from dental pulp. Transplantation 80: 836-842.

Pisciotta A, Riccio M, Carnevale G, Beretti F, Gibellini L, Maraldi T, Cavallini GM, Ferrari A, Bruzzesi G, De Pol A (2012) Human serum promotes osteogenic differentiation of human dental pulp stem cells in vitro and in vivo. PloS One 7: e50542.

Reya T, Clevers H (2005) Wnt signalling in stem cells and cancer. Nature 434: 843-850.

Rodilla V, Villanueva A, Obrador-Hevia A, RobertMoreno A, Fernandez-Majada V, Grilli A, Lopez- 
Bigas N, Bellora N, Alba MM, Torres F, Dunach M, Sanjuan X, Gonzalez S, Gridley T, Capella G, Bigas A, Espinosa L (2009) Jagged1 is the pathological link between Wnt and Notch pathways in colorectal cancer. Proc Natl Acad Sci U S A 106: 6315-6320.

Rogers CD, Jayasena CS, Nie S, Bronner ME (2012) Neural crest specification: tissues, signals, and transcription factors. Wiley Interdiscip Rev Dev Biol 1: 52-68.

Rosa V, Dubey N, Islam I, Min KS, Nor JE (2016) Pluripotency of stem cells from human exfoliated deciduous teeth for tissue engineering. Stem Cells Int 2016: 5957806.

Saunders A, Faiola F, Wang J (2013) Concise review: pursuing self-renewal and pluripotency with the stem cell factor Nanog. Stem Cells 31: 1227-1236.

Scheller EL, Chang J, Wang CY (2008) Wnt/betacatenin inhibits dental pulp stem cell differentiation. J Dent Res 87: 126-130.

Schindelin J, Arganda-Carreras I, Frise E, Kaynig V, Longair M, Pietzsch T, Preibisch S, Rueden C, Saalfeld S, Schmid B, Tinevez JY, White DJ, Hartenstein V, Eliceiri K, Tomancak P, Cardona A. (2012) Fiji: an open-source platform for biologicalimage analysis. Nat Methods 9: 676-682.

Schiraldi C, Stellavato A, D'Agostino A, Tirino V, d'Aquino R, Woloszyk A, De Rosa A, Laino L, Papaccio G, Mitsiadis TA (2012) Fighting for territories: time-lapse analysis of dental pulp and dental follicle stem cells in co-culture reveals specific migratory capabilities. Eur Cell Mater 24: 426-440.

Shi Y, Shu B, Yang R, Xu Y, Xing B, Liu J, Chen L, Qi S, Liu X, Wang P, Tang J, Xie J (2015) Wnt and Notch signaling pathway involved in wound healing by targeting c-Myc and Hes1 separately. Stem Cell Res Ther 6: 120.

Shyamala K, Yanduri S, Girish HC, Murgod S (2015) Neural crest: the fourth germ layer. J Oral Maxillofac Pathol 19: 221-229.

Simandi Z, Horvath A, Wright LC, CuarantaMonroy I, De Luca I, Karolyi K, Sauer S, Deleuze JF, Gudas LJ, Cowley SM, Nagy L (2016) OCT4 acts as an integrator of pluripotency and signal-induced differentiation. Mol Cell 63: 647-661.

Stuhlmiller TJ, Garcia-Castro MI (2012) Current perspectives of the signaling pathways directing neural crest induction. Cell Mol Life Sci 69:3715-3737.

Takahashi K, Okita K, Nakagawa M, Yamanaka S (2007) Induction of pluripotent stem cells from fibroblast cultures. Nat Protoc 2: 3081-3089.

Tatullo M, Falisi G, Amantea M, Rastelli C, Paduano F, Marrelli M (2015) Dental pulp stem cells and human periapical cyst mesenchymal stem cells in bone tissue regeneration: comparison of basal and osteogenic differentiated gene expression of a newly discovered mesenchymal stem cell lineage. J Biol Regul Homeost Agents 29: 713-718.

Thomas S, Thomas M, Wincker P, Babarit C, Xu P, Speer MC, Munnich A, Lyonnet S, Vekemans M, Etchevers HC (2008) Human neural crest cells display molecular and phenotypic hallmarks of stem cells. Hum Mol Genet 17: 3411-3425.

Vasanthan P, Govindasamy V, Gnanasegaran N, Kunasekaran W, Musa S, Abu Kasim NH (2015) Differential expression of basal microRNAs' patterns in human dental pulp stem cells. J Cell Mol Med 19: 566-580.

Wang J, Levasseur DN, Orkin SH (2008) Requirement of Nanog dimerization for stem cell self-renewal and pluripotency. Proc Natl Acad Sci U S A 105: 6326-6331.

Wilson R, Urraca N, Skobowiat C, Hope KA, Miravalle L, Chamberlin R, Donaldson M, Seagroves TN, Reiter LT (2015) Assessment of the tumorigenic potential of spontaneously immortalized and hTERTimmortalized cultured dental pulp stem cells. Stem Cells Transl Med 4: 905-912.

Wu W, Zhou J, Xu CT, Zhang J, Jin YJ, Sun GL (2015) Derivation and growth characteristics of dental pulp stem cells from patients of different ages. Mol Med Rep 12: 5127-5134.

Xiao L, Tsutsui T (2013) Characterization of human dental pulp cells-derived spheroids in serum-free medium: stem cells in the core. J Cell Biochem 114: 2624-2636.

Yan X, Qin H, Qu C, Tuan RS, Shi S, Huang GT (2010) iPS cells reprogrammed from human mesenchymal-like stem/progenitor cells of dental tissue origin. Stem Cells Dev 19: 469-480.

Yiew NK, Chatterjee TK, Tang YL, Pellenberg R, Stansfield BK, Bagi Z, Fulton DJ, Stepp DW, Chen W, Patel V, Kamath VM, Litwin SE, Hui DY, Rudich SM, Kim HW, Weintraub NL (2017) Novel role for Wnt inhibitor APCDD1 in adipocyte differentiation: implications for diet-induced obesity. J Biol Chem 292: 6312-6324.

Yu J, He H, Tang C, Zhang G, Li Y, Wang R, Shi J, Jin Y (2010) Differentiation potential of STRO-1+ dental pulp stem cells changes during cell passaging. BMC Cell Biol 11: 32.

Yu J, Vodyanik MA, Smuga-Otto K, AntosiewiczBourget J, Frane JL, Tian S, Nie J, Jonsdottir GA, Ruotti V, Stewart R, Slukvin II, Thomson JA (2007) Induced pluripotent stem cell lines derived from human somatic cells. Science 318: 1917-1920.

Zhang Z, Deb A, Zhang Z, Pachori A, He W, Guo J, Pratt R, Dzau VJ (2009) Secreted frizzled related protein 2 protects cells from apoptosis by blocking the effect of canonical Wnt3a. J Mol Cell Cardiol 46: 370-377.

\section{Discussion with Reviewers}

Benjamin Fournier: Do you think that the supplements you used in this study (especially BIO) may become part of the serum replacement strategy, when growing DPSC? Did you experiment (or did you plan to experiment) the use of these factors on other stem cells? 
Authors: The main advantage of the use of FBS is that it permits a very rapid amplification of the collected cells for various uses (e.g. cell therapy). This is particularly important for the dental pulp where the starting collected material is usually very small, compared to other stem cell sources. However, the downside is that upon continuous amplification, stem cell populations tend to exhaust (i.e. lose proliferation and multilineage differentiation capacity). One important implication of this work was that DPSC exhaustion by continuous exposure to FBS could be at least partially prevented by transiently boosting, just $48 \mathrm{~h}$ before use, the activity of Notch/Wnt pathways - by means of small molecules and/or recombinant proteins - which would enhance stemness traits of DPSCs cultures for in vitro differentiation. We really do not think that these treatments alone could work as a serum replacement strategy, but rather as a complementary mechanism to prevent stem cell exhaustion after several rounds of culture passaging.
We do not plan to extend these experiments to other stem cell sources yet, but we think it would be a very interesting idea.

Marco Tatullo: Authors have clearly reported how the potency of DPSCs can be enhanced by short preconditioning treatments with Wnt activators. Is it reasonable to consider such treatments as part of a functionalised scaffold to be used in a specific site to aid regeneration?

Authors: We definitely think this is a very interesting idea, especially for Wnt-3a, which is an extracellular water-soluble protein and could be easily incorporated into a functionalised scaffold by a team expert in biomaterials research.

Editor note: The scientific editor for this paper was Christine Hartmann. 